\title{
Assimilating high-resolution salinity data into a model of a partially mixed estuary
}

Jiangtao Xu

University of Maryland

Shenn-Yu Chao

Univeristy of Maryland

Raleigh R. Hood

Harry V. Wang

Virginia Institute of Marine Science, wang@vims.edu

Follow this and additional works at: https://scholarworks.wm.edu/vimsarticles

Part of the Marine Biology Commons

\section{Recommended Citation}

Xu, Jiangtao; Chao, Shenn-Yu; Hood, Raleigh R.; and Wang, Harry V., "Assimilating high-resolution salinity data into a model of a partially mixed estuary" (2002). VIMS Articles. 283.

https://scholarworks.wm.edu/vimsarticles/283 


\title{
Assimilating high-resolution salinity data into a model of a partially mixed estuary
}

\author{
Jiangtao Xu, Shenn-Yu Chao, and Raleigh R. Hood \\ University of Maryland Center for Environmental Science, Cambridge, Maryland, USA \\ Harry V. Wang \\ Department of Physical Sciences, Virginia Institute of Marine Science, Gloucester Point, Virginia, USA \\ William C. Boicourt \\ University of Maryland Center for Environmental Science, Cambridge, Maryland, USA
}

Received 1 September 2000; revised 18 June 2001; accepted 8 November 2001; published 16 July 2002.

[1] A three-dimensional circulation model of the Chesapeake Bay is used to validate a simple data assimilation scheme, using high-resolution salinity data acquired from a shiptowed undulating vehicle (a Scanfish). The simulation period spans the entire year of 1995 during which the high-resolution Scanfish data were available in July and October, lasting a few days each. Since Scanfish data were irregularly distributed in time and space, only salinity fields are nudged in the model for simplicity. Model improvements through data assimilation are evaluated from a pair of experiments: one with data assimilation and one without. Data from scattered Chesapeake Bay Program monitoring stations and a few stations maintained by the National Ocean Service inside the bay are used independently to check the model performance. In general, the simple assimilation scheme leads to visibly improved density structures in the upper and middle reaches of the bay. The improvement in the lower bay is equally pronounced after data assimilation but diminishes in a shorter timescale because of faster flushing from the adjacent coastal ocean. Moderate to weak nudging normally enhances the gravitational circulation. Strong nudging may produce transient overshooting, during which the gravitational circulation is renewed vigorously. INDEX TERMS: 4235 Oceanography: General: Estuarine processes; 4243 Oceanography: General: Marginal and semienclosed seas; 3337 Meteorology and Atmospheric Dynamics: Numerical modeling and data assimilation; KEYWORDS: data assimilation, modeling, estuary, Chesapeake Bay, salinity

\section{Introduction}

[2] In modeling partially mixed estuaries a major difficulty to overcome is the numerical damping. The numerical representation of three-dimensional flow and density fields by a finite number of computation cells invariably increases friction. Part of the enhanced friction arises from grid-scale mixing because friction coefficients must be made proportional to a power of grid spacing to achieve computational stability. Numerical form drag also enhances friction when irregular coastlines and bottom topographies are approximated by groups of computation cells. While these problems are common to all ocean models, they become particularly acute in models of long and narrow estuaries with excessive coastline and topography irregularities. The bottom inflow must follow a long and often sinuous path to enter, upwell, and return seaward. To overcome numerical damping, it is often necessary to enhance bottom inflow of seawater from the mouth region in order to produce a realistic two-layered circulation well inside an estuary.

Copyright 2002 by the American Geophysical Union. 0148-0227/02/2000JA000626
[3] There are two ways to enhance further model realism. One way is to improve grid resolution at the expense of computation speeds. The other way is through assimilation of high-resolution data. With the availability of satellite altimeter and climatological data sets, data assimilation is now widely used in large-scale ocean models, and dynamic principles have been developed for the purpose of nudging several variables simultaneously [e.g., Ezer and Mellor, 1994; Forbes and Brown, 1996; Wu et al., 1999]. Similar efforts in shallow reaches of the ocean are deliberately simplified for lack of climatological data sets and reliable altimeter data. For example, Spitz and Klinck [1998] used an adjoint variational method along with tide gauge data from a few stations to improve sea level predictions in a twodimensional tidal model of the Chesapeake Bay. Similar methods were also used to assimilate current velocity data into shallow water equation models of Massachusetts Bay [Bogden et al., 1996] and Long Island Sound [Bogden and O'Donnell, 1998].

[4] Because of the resolution problem, highly nonlinear phenomena such as internal bore intrusion and sill-induced hydraulic jumps in estuaries are often smeared out by friction in numerical models. In this light, successful 


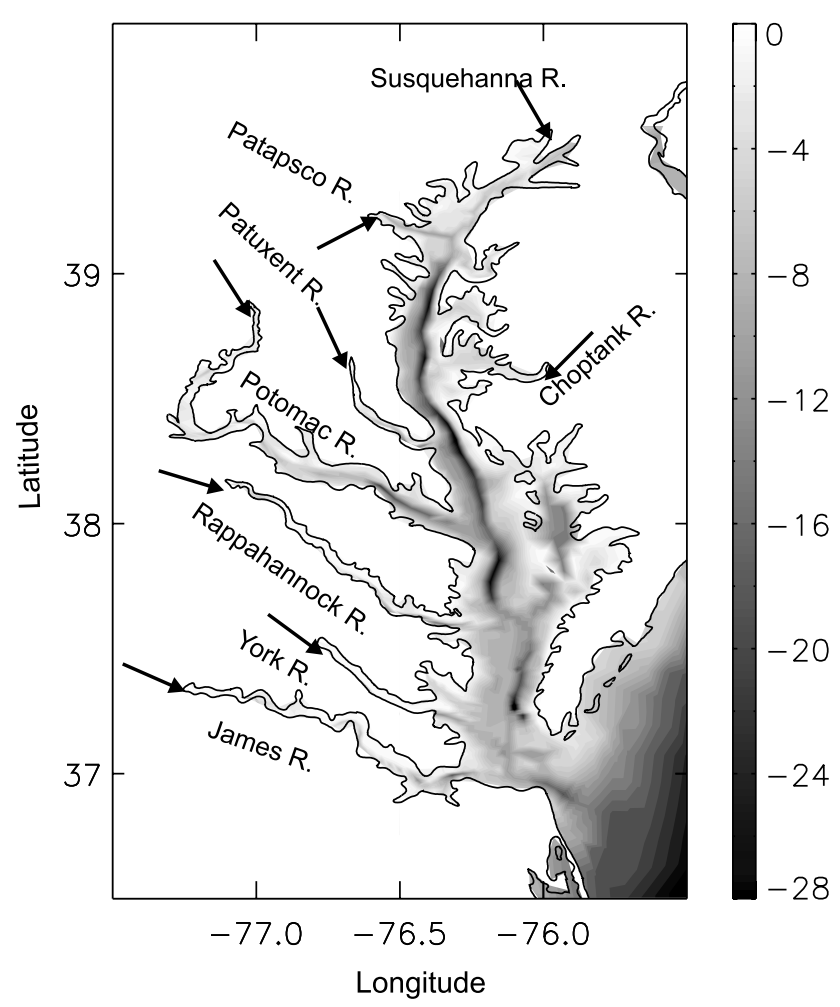

Figure 1. Bathymetry of the Chesapeake Bay and adjacent coastal area. Major tributaries are marked. Depth scales are in the unit of meters.

assimilation of high-resolution data would be highly desirable for it allows modelers to reproduce these physical processes in more realistic settings. This remains as a lofty goal at the present time.

[5] Recent advances in undulating oceanographic recorders (such as Scanfish manufactured by a Danish company Geological \& Marine Instrumentation) offer an alternative. Through rapid vertical undulations, a ship-towed vehicle can provide a reasonably synoptic, three-dimensional view of the density structure in a large body of shallow waters. The high-resolution data, though irregularly distributed in space and time, may be assimilated into numerical models. Ideally, one would like to derive climatological data sets for shallow bodies of waters from repeated sampling over many years and assimilate climatological data into models in a dynamically consistent fashion. This option is presently not feasible for obvious reasons.

[6] An attempt is made below to assimilate the Scanfish data into a Chesapeake Bay three-dimensional circulation model. Year 1995 was chosen because it was the first year the high-resolution salinity data became available. Further, the hydrodynamic model simulation had not been carried out and verified beyond 1995 at the time this research was initiated. The simulation period spans the entire year of 1995, during which two rapid sampling cruises covering the main stem of the bay were made in July and October. In the same year, 49 main stem monitoring stations were maintained by Chesapeake Bay Program of the Environmental Protection Agency. Each station was sampled 16-20 times in the year at irregular time intervals. Only Scanfish data from the July and October cruises are assimilated. Selected salinity data from the 49 fixed stations are used to evaluate the performance of the data assimilation scheme.

[7] Intuitively, direct assimilation of hydrographic data into a model seems like an effective way to improve model realism. The ideal scenario is that assimilation improves the density structure, and the improved density field supports a more realistic circulation field. While this is generally true, the improvement does not come without penalties. In the subject at hand it is found that quick injections of data may trigger brief moments of readjustment in gravitational circulation. Circulation during brief periods of gravitational readjustment may be unrealistic. In this light the speed of data injection must be optimized so that the gain will outweigh the loss.

[8] The oceanographic setting and data availability are described in section 2. A hydrodynamic model of the Chesapeake Bay is described in section 3. The data assimilation scheme is discussed in section 4. The undesirable consequence of data assimilation, i.e., the gravitational readjustment, is elaborated in section 5. Benefits brought about by data assimilation are summarized in section 6 . This work is concluded in section 7 .

\section{Oceanographic Setting}

[9] A deep channel running north-south more or less along the western side of the main stem dominates the bathymetry in the middle reaches of the Chesapeake Bay (Figure 1). The main channel, bounded to the south by a sill at about $37.6^{\circ} \mathrm{N}$, is completely closed below the sill depth of about $14 \mathrm{~m}$. South of $37.6^{\circ} \mathrm{N}$, the deep channel becomes somewhat shallower and ill defined, often branching in multiple directions. Between $37.6^{\circ}$ and $39^{\circ} \mathrm{N}$ the main deep channel harbors a rather persistent, river-induced two-layered circulation, although the gravitational circulation is often influenced by winds and stratification [Goodrich et al., 1987]. Along the main stem of the bay, drainage from eight major tributaries (Susquehanna, Patapsco, Patuxent, Potomac, Rappahannock, York, James, and Choptank) contributes to most of the river input. The Susquehanna River in the northern extreme of the bay provides the largest freshwater influx among the eight, approximately one half of the total freshwater input. Tidal forcing is modest inside the bay with tidal range rarely exceeding $1 \mathrm{~m}$. Winds are generally episodic with dominant periods of $2-7$ days. In the upper and middle reaches of the bay, northwesterly winds dominate in winter months (November-February) but are more frequently disrupted by southerly winds of several days each in summer.

[10] Figure 2 shows daily discharge rates from the four largest tributaries (Susquehanna, Potomac, James, and Rappahannock) for the entire year of 1995 , which was perceived as an abnormally dry year. Discharge from other rivers was considerably lower. Discharge was generally high from mid-January to April, further enhanced by several peaks of 5-10 days duration. It decreased markedly in summer and was relatively high again in late fall. When averaged over sufficiently long periods to filter out wind and tidal effects, the annual variation of subtidal circulation in the Chesapeake Bay is expected to be dominated by the strength of freshwater discharge. See Goodrich et al. [1987] for some observations. 

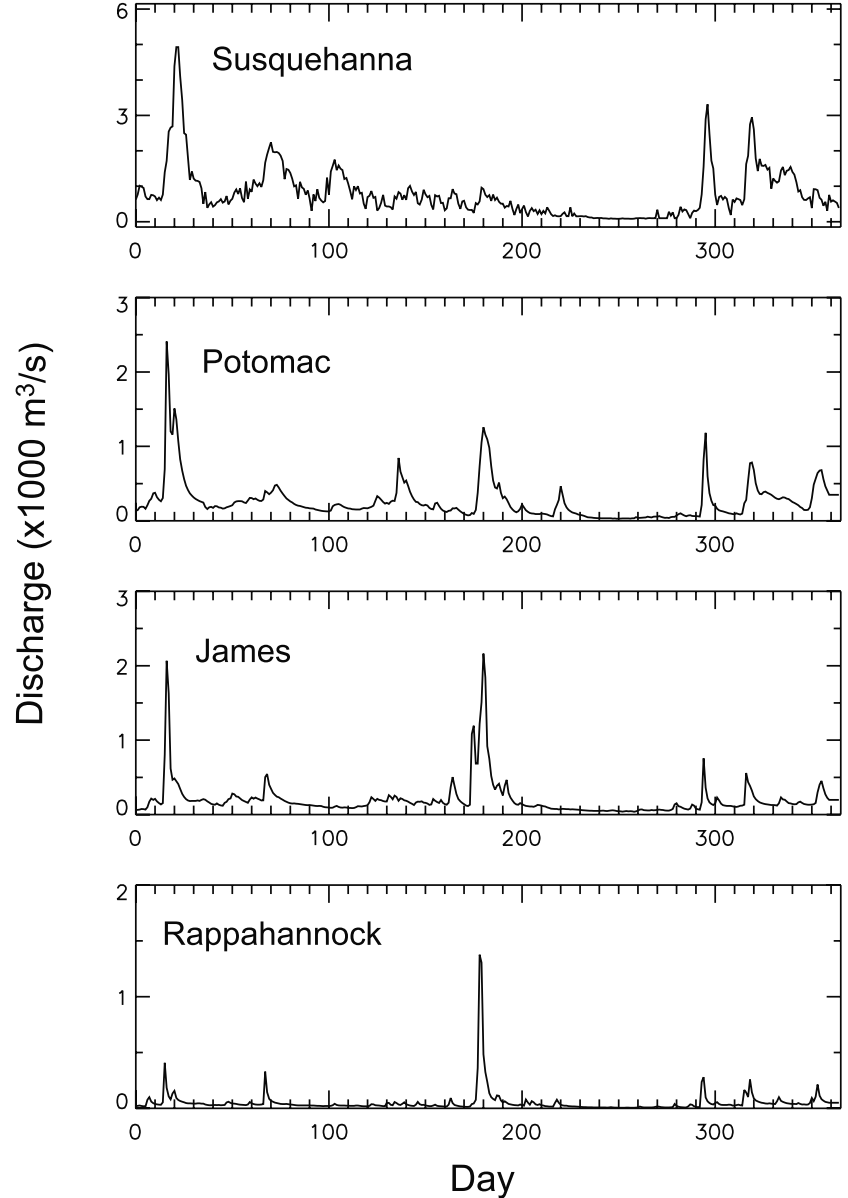

Figure 2. Daily freshwater discharge in units of $10^{3} \mathrm{~m}^{3} \mathrm{~s}^{-1}$ from Susquehanna, Potomac, James, and Rappahannock Rivers in 1995.

[11] Figure 3 shows 24 Scanfish transects across the main stem of the Chesapeake Bay. Temperature and salinity were sampled along these transects from 19 to 22 July and from 24 to 26 October 1995. Starting from transect 1 across the mouth of Chesapeake Bay, transects are visited sequentially as the ship moves up the estuary. Moving at an average speed of 6 knots, the ship covers each transect in about half an hour to 4 hours, and it takes about 3 days to complete a basin-wide survey. The Scanfish follows slanted paths up and down the water column with inclination angles around $6^{\circ}$, sampling at time intervals of 0.5 s. During the July cruise, data along transects 1,4 , and $7-12$ in the lower bay were unfortunately lost. In consequence, effects of data assimilation in July come mostly from inner reaches of the bay.

[12] Selected salinity stations maintained by Chesapeake Bay Program are marked by dots in Figure 3. These stations were visited 16-20 times in 1995 at somewhat irregular intervals. At each station, salinity profiles were measured with a vertical resolution of $1 \sim 2 \mathrm{~m}$. These salinity profiles provide an independent data set that can be used to assess how well the data assimilation scheme works. Two temperature stations at Tolchester Beach and Solomons Island, marked by crosses in Figure 3, were maintained by the National Ocean Service (NOS) of National Oceanic and
Atmospheric Administration (NOAA) in 1995 (http:// www.co-ops.nos.noaa.gov/data_res.html). These time series can also be used for model verification, although our major emphasis is on salinity as the major indicator of water density in the Bay.

\section{Hydrodynamic Model}

[13] The model, originally developed by Sheng [1986], was subsequently modified extensively by the U.S. Waterways Experiment Station (WES) for application to Chesapeake Bay [Johnson et al., 1991; Wang and Chapman, 1995]. Under Boussinesq and hydrostatic approximations the hydrodynamic model solves for salinity, temperature, water level elevation, and velocities in three dimensions. There are up to 19 layers in the vertical with a uniform layer thickness of $1.52 \mathrm{~m}$, except that the top layer thickness fluctuates with sea level. Horizontally, the governing equations in the Cartesian coordinate system are recast in a boundary-fitted curvilinear coordinate system (Figure 4) to cope with the irregular shoreline configuration and deep channel orientation. The model domain extends offshore to include a piece of coastal ocean with

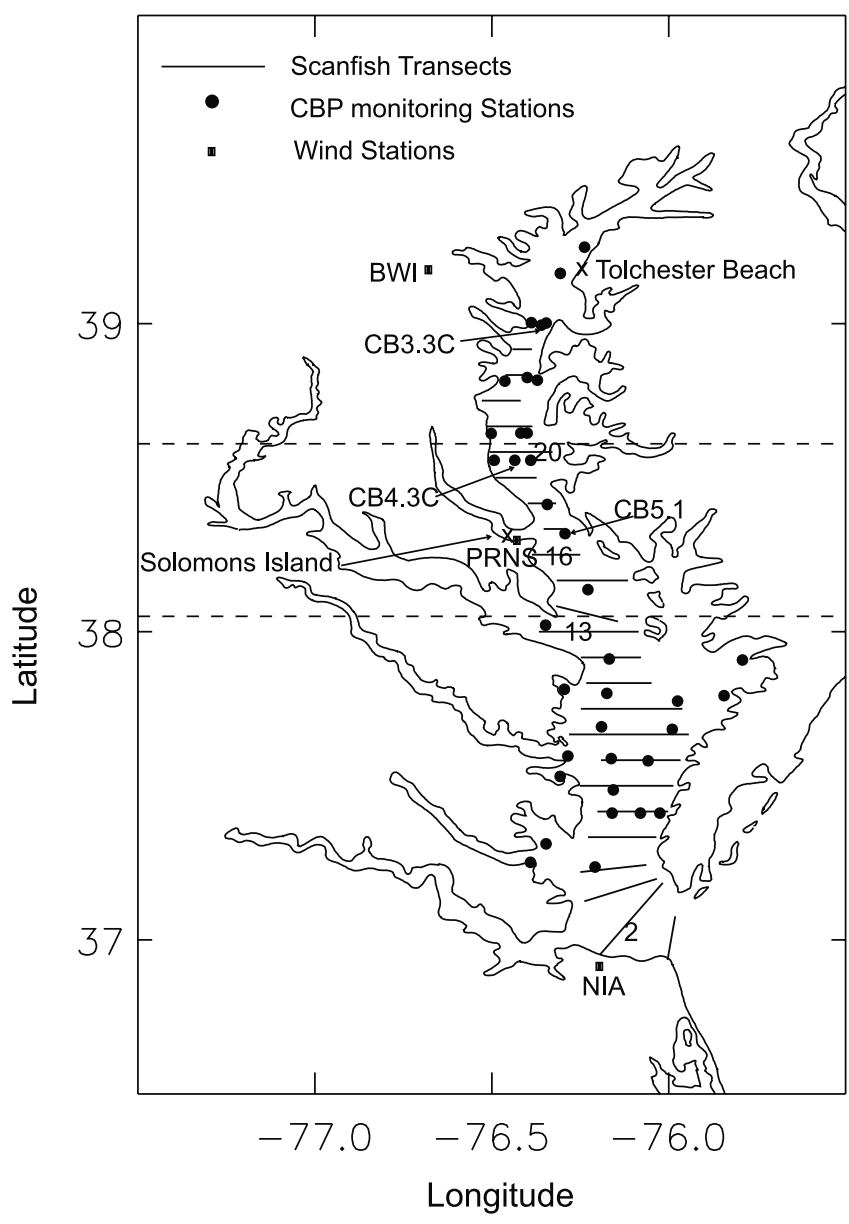

Figure 3. Scanfish transects and selected salinity stations in 1995. Salinity stations were maintained by Chesapeake Bay Program (CBP); selected station identities mentioned in the text are given. Zonal dashed lines delineate upper, middle, and lower reaches of the bay. 


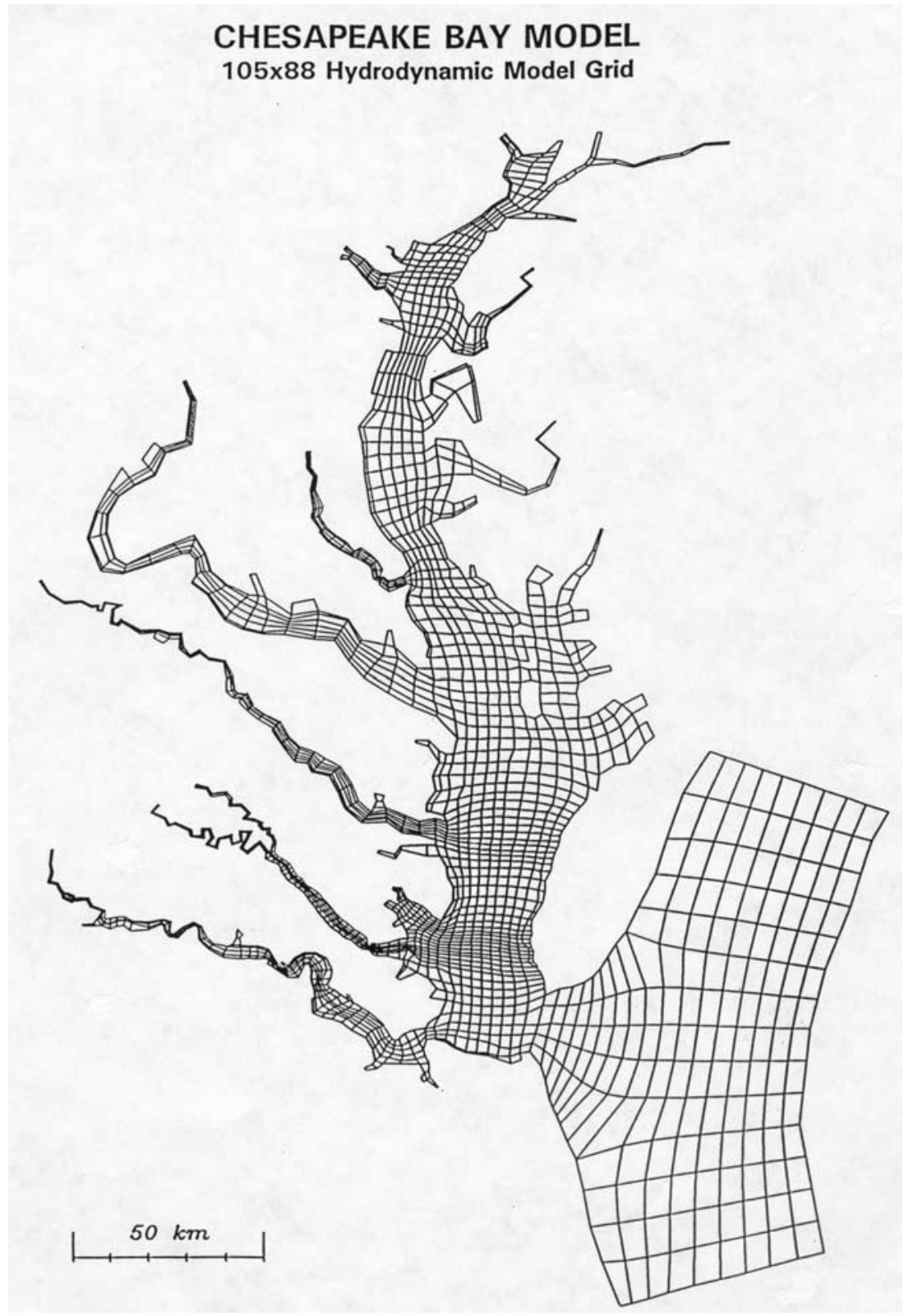

Figure 4. Boundary-fitted grid of the Chesapeake Bay hydrodynamic model.

coarse resolution. The coastal ocean is included mainly as a buffer zone to facilitate free exchanges across the bay mouth. Inside the bay, typical grid size ranges from 1 to $5 \mathrm{~km}$ in the main stem of the bay; bottom topographic irregularities with horizontal scales in and below this range are truncated by the model. Further, the prominent sill bounding the main deep channel in the south, located between the mouths of Rappahannock and Potomac Rivers, is marginally resolved. In spite of the coarse resolution, essential circulation features, such as the two-layered circulation in the main channel and major tributaries, can be reproduced by the model [Johnson et al., 1991; Hood et al., 1999]. Similar to a host of primitive-equation models such as Blumberg and Mellor [1987], the staggered Arakawa-C grid system is used in both horizontal and vertical directions of the computation domain. The vertical eddy viscosity and diffusivity are computed from mean flow and stratification characteristics using the secondorder $k-\varepsilon$ turbulent closure scheme [see, e.g., Kundu, 1980; Launder and Spalding, 1974]. A quadratic stress is exerted at the bottom, assuming the bottom boundary layer is logarithmic over a bottom roughness height of $0.05 \mathrm{~cm}$. Coefficients of horizontal eddy viscosity and diffusivity are set to $10^{4} \mathrm{~cm}^{2} \mathrm{~s}^{-1}$.

[14] Originally, the initial three-dimensional salinity and temperature fields were constructed using the historical field data in January averaged over many years. Since initialization, this model simulation has been extended from 1985 to 1994 by WES. We used the model output at the end of 1994 as the initial condition for salinity and temperature fields. The initial velocity field was taken to be zero, and the water surface was initially set at the mean sea level.

[15] The model is subsequently forced by open ocean tides, winds, freshwater inflows, and heat exchange at the 
water surface through 1995. Further, salinity and temperature fields were also prescribed on offshore open boundaries using monthly Levitus climatology data [Levitus, 1982] combined with field data at Duck, North Carolina $\left(36.1833^{\circ} \mathrm{N}, 75.7467^{\circ} \mathrm{W}\right)$, acquired daily (with occasional lapses) by the Field Research Facility of the U.S. Army Corps of Engineers. Daily freshwater inflow with zero salinity and time-varying temperature was prescribed for the eight major tributaries; arrows in Figure 1 mark inflow locations. On each inflow cross section the incoming current is uniform with time-varying speeds regulated by the daily freshwater discharge rate.

[16] Hourly wind stress in the lower and middle reaches of the bay was linearly interpolated from data at the Norfolk International Airport (NIA), Patuxent River Naval Station (PRNS), and Baltimore-Washington International Airport (BWI). Their locations are marked by solid squares in Figure 3. North of BWI, wind stress is assumed to be identical to that at BWI. Empirical factors for different regions were used to extrapolate winds over land to winds over water. Daily air-water heat exchange was computed from data taken at the Patuxent meteorological station using the formulation of Edinger et al. [1974]. Ideally, meteorological stations over the water are desirable, but few offshore stations were available in 1995. In constructing the wind field for the bay model it should be noted that longitudinal winds are much more effective than lateral winds in driving circulation along the main stem of the bay [Wang, 1979a, 1979b]. The linear interpolation among the three meteorological stations (NIA, PRNS, and BWI) is intended to improve spatial resolution of longitudinal winds along the main axis of the bay. One reviewer of this manuscript pointed out two additional records at Solomons Island and Tolchester Beach, maintained by NOS, NOAA. From a basin-wide perspective the Solomons Island station and PRNS are practically at the same location. The inclusion of Solomons Island therefore will not improve the spatial resolution of winds along the main axis of the bay. Tolchester Beach station and BWI are also at about the same latitude. If the two wind records differ substantially, the inclusion of Tolchester Beach will likely improve lateral resolution of wind forcing in the upper reaches of the bay but does little to enhance longitudinal resolution of the wind field. If winds at Tolchester Beach and BWI do not differ substantially, then there is no reason to include it. To investigate further, we have performed cross-spectral analysis to document the relationship between winds at Solomons Island and PRNS and at Tolchester Beach and BWI. Of major concern are low-frequency longitudinal winds with periods longer than a few days along the main axis of the bay. High-frequency winds and cross-estuary winds are basically noise generators, ineffective to drive basinscale subtidal circulation. In periods longer than about 2.5 days the coherence squared between Solomons Island and PRNS is about 0.8 for longitudinal winds and approaches 0.7 for lateral winds. The corresponding coherence squared between Tolchester Beach and BWI approaches 0.76 for longitudinal winds and 0.68 for lateral winds. Further, the phase lag between each pair of stations is generally less than a few hours for longitudinal winds. Therefore the subtidal circulation in the main stem of the bay will not be impacted significantly whether the additional wind records are included or not. As a consistency check, we have also compared the modeled and observed surface water temperature at Tolchester Beach and Solomons Island in 1995. The result, to be shown later in Figure 6, shows reasonable agreement even without the inclusion of the two additional wind records, lending support to the foregoing argument.

[17] Open ocean boundary sea level was updated using data from stations at Wachapregue, Virginia $\left(37.6067^{\circ} \mathrm{N}\right.$, $75.6867^{\circ} \mathrm{W}$, ) and Duck, North Carolina $\left(36.1833^{\circ} \mathrm{N}\right.$, $75.7467^{\circ} \mathrm{W}$ ), obtained from NOS, NOAA. These coastal sea level data were first extrapolated offshore on the basis of Green's law [Ippen, 1966]. Namely, tidal amplitudes are assumed to be inversely proportional to the quarter power of local water depth. In the alongshore direction, tidal amplitudes are linearly interpolated on the offshore open boundary. While water level fluctuations are prescribed on open ocean boundaries, the incoming and outgoing currents are induced by water level gradients normal to these boundaries.

[18] The model solves external and internal mode equations separately. The external mode consists of equations for the water surface elevation and vertically averaged flows in two horizontal directions. The internal mode computes the vertical shear of horizontal velocities, vertical velocity, temperature, and salinity. Time steps for the external and internal modes are both set at $300 \mathrm{~s}$. The larger than normal time step for the external mode is made possible by an implicit solver, which relaxes the stringent requirement for small time steps set by the Courant-Friedrichs-Levy computational stability criterion.

[19] Before data assimilation the hydrodynamic model was tuned to reproduce observed surface salinity in the upper and middle reaches of the deep channel. The initial tuning includes minor adjustment in the bottom topography, vertical mixing parameters, and salinity on open ocean boundaries. Figure 5 shows the model-produced time series of surface salinity at stations CB3.3C and CB5.1 in the upper and middle reaches of the deep channel, respectively. Superimposed are corresponding data points that agree with the model reasonably well. The quality control at the two points over the deep channel ensures comparable model performance in the vicinity, at least near the water surface.

[20] Figure 6 compares the modeled and observed water surface temperature at Tolchester Beach and Solomons Island in 1995. The model outputs were retrieved at halfhour intervals, while the observed time series were at hourly intervals. In general, the model reproduces the seasonal trend of water surface temperature reasonably well, although the model tends to overestimate surface temperature in winter months. Note that the hydrodynamic model does not have an ice layer component and therefore cannot simulate occasional winter freezing events in shallow reaches of the basin. This deficiency is likely to cause some discrepancies in winter. The problem is not serious because the discrepancy diminishes quickly in warmer months.

[21] Leaving the model-data agreement aside, sizable discrepancies still exist at depths and laterally. Figure 7 illustrates the general pattern of discrepancies by comparing model results with Scanfish data along two selected transects (sections 13 and 20 in Figure 3) in July. Figure 7 (bottom) shows sections of salinity fields derived from Scanfish data, while Figure 7 (top) shows corresponding 


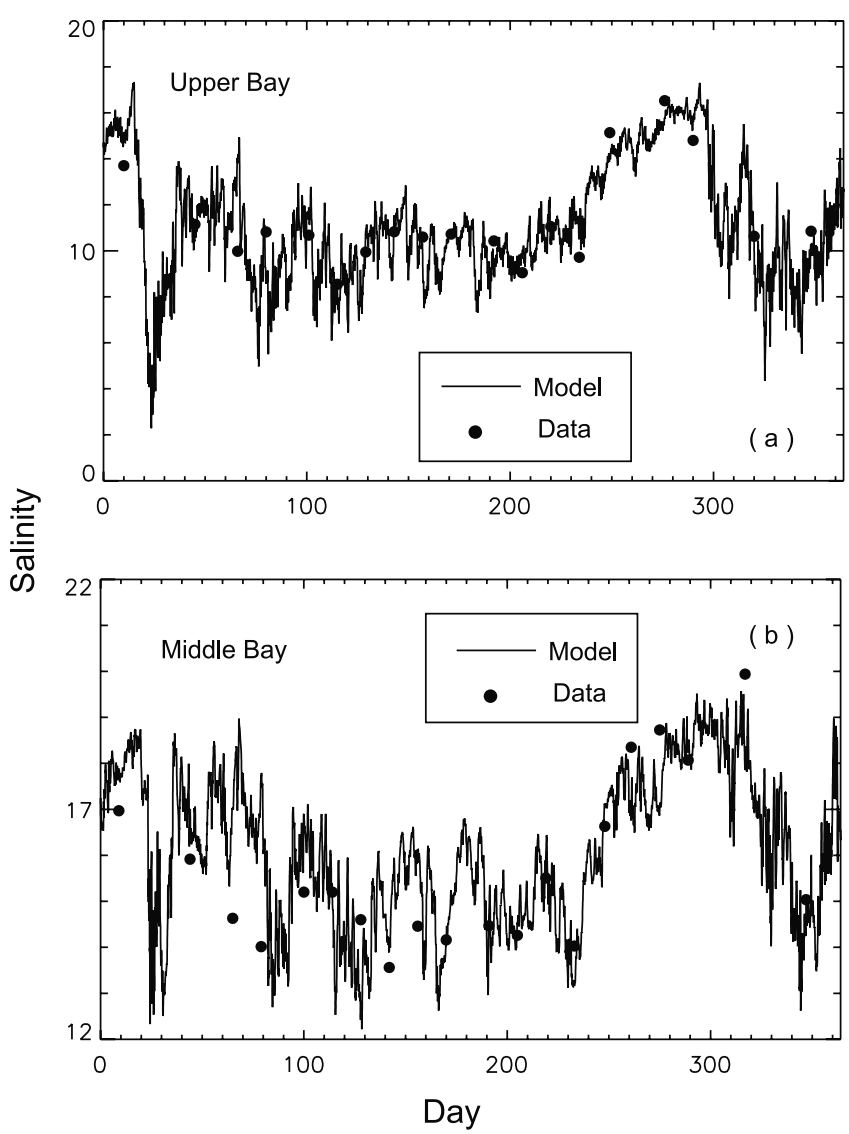

Figure 5. Model-derived time series of surface salinity and observed salinity data at (a) station $\mathrm{CB} 3.3 \mathrm{C}$ and (b) station CB5.1 in 1995.

sections retrieved from the model, following the same tracks and sampling intervals of the Scanfish. Section 13 (Figure 7a) and section 20 (Figure 7b) are in the middle and upper reaches of the bay, respectively. The comparison points out a dominant trend. Namely, the model tends to overestimate salinity at depths and the deviation increases toward lower reaches of the bay.

[22] A similar comparison in October (Figure 8) leads to the same conclusion. Because of the availability of transects in lower reaches of the bay, section 2 (Figure 8a) and section 16 (Figure 8b) are chosen to facilitate the comparison in lower and middle reaches of the bay, respectively. In the lower bay (Figure 8a) the model-derived salinity is considerably higher than observations, and the discrepancy increases with depth. In the middle reaches (Figure 8b) the modeled salinity structures compare favorably with those observed.

[23] Figure 9 shows longitudinal sections of monthly averaged circulation and salinity fields derived from the model in February (Figure 9a) and October (Figure 9b). The vertical slice follows the center axis of the deep channel southward to the mouth of Rappahannock River and thereafter extrapolates farther southward to the southern land boundary. The monthly averaging removes most of the wind and tidal influences, and the residual circulation is mostly gravitational. The peak discharge from tributaries in January results in a pronounced two-layered circulation in February.
The bottom inflow is visibly much stronger than the surface outflow because of the lateral confinement at depths. October is in the end of a long dry period, and the twolayered circulation is much weaker. Waters in the deep channel also becomes saltier in the dry period.

[24] Conceivably, further tuning of the model will further reduce the discrepancies as illustrated in Figures 7 and 8, but the point of diminishing return will be reached soon if the model resolution remains the same. With coarse resolution the bottom inflow is partially choked by numerical damping near the estuary mouth and therefore must be enhanced in order to reproduce observed salinity structures in the middle and upper reaches of the bay. In consequence, the model-produced bottom inflow becomes saltier, especially in the lower reaches of the bay. The intention of data assimilation is therefore to reduce modeled salinity at depths and in lower reaches of the bay.

\section{Data Assimilation Scheme}

[25] The hydrodynamic model receives irregularly spaced time series of Scanfish data through the salinity equation, using a Newtonian relaxation scheme [Anthes, 1974]. Since salinity is the major indicator of water density in this region, temperature data are excluded from assimilation for simplicity. Let $x$ be the longitudinal axis, $y$ be the lateral axis, and $z$ be the vertical axis. At a given time $\left(t=t_{0}\right)$ a model

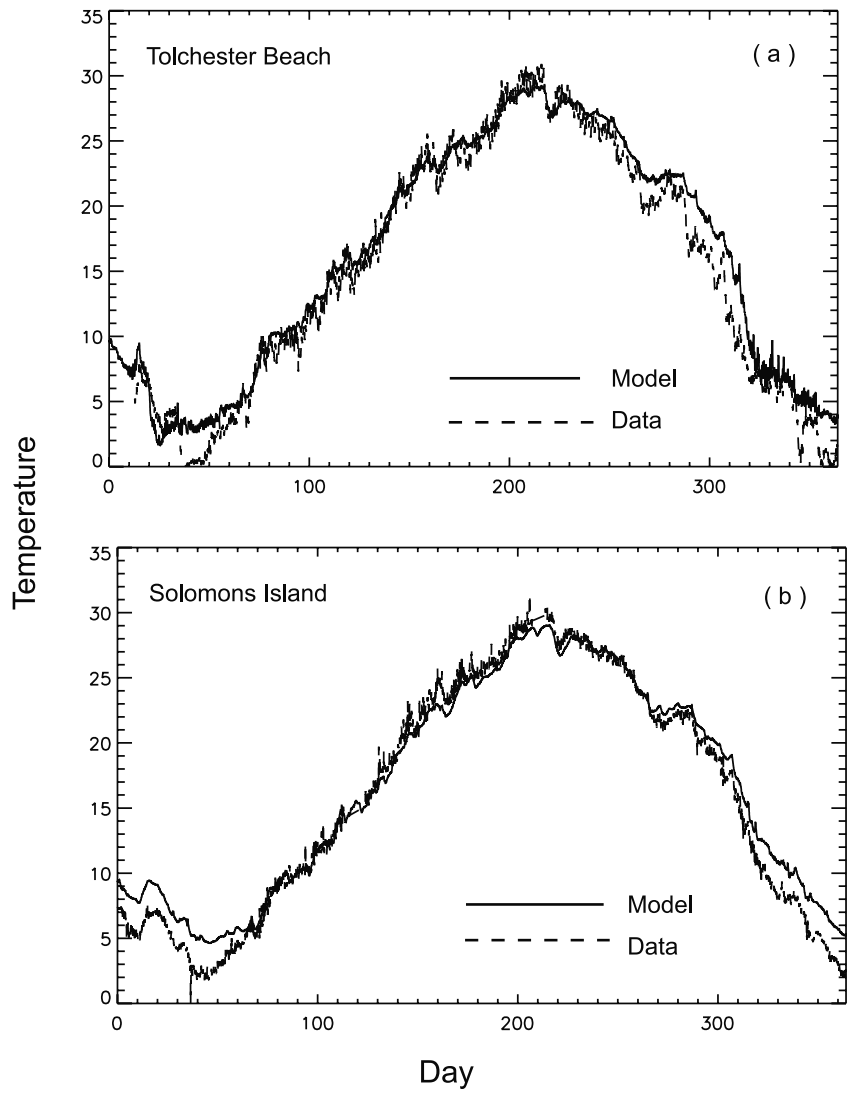

Figure 6. Model-derived and observed time series of water surface temperature at (a) Tolchester Beach and (b) Solomons Island in 1995. 

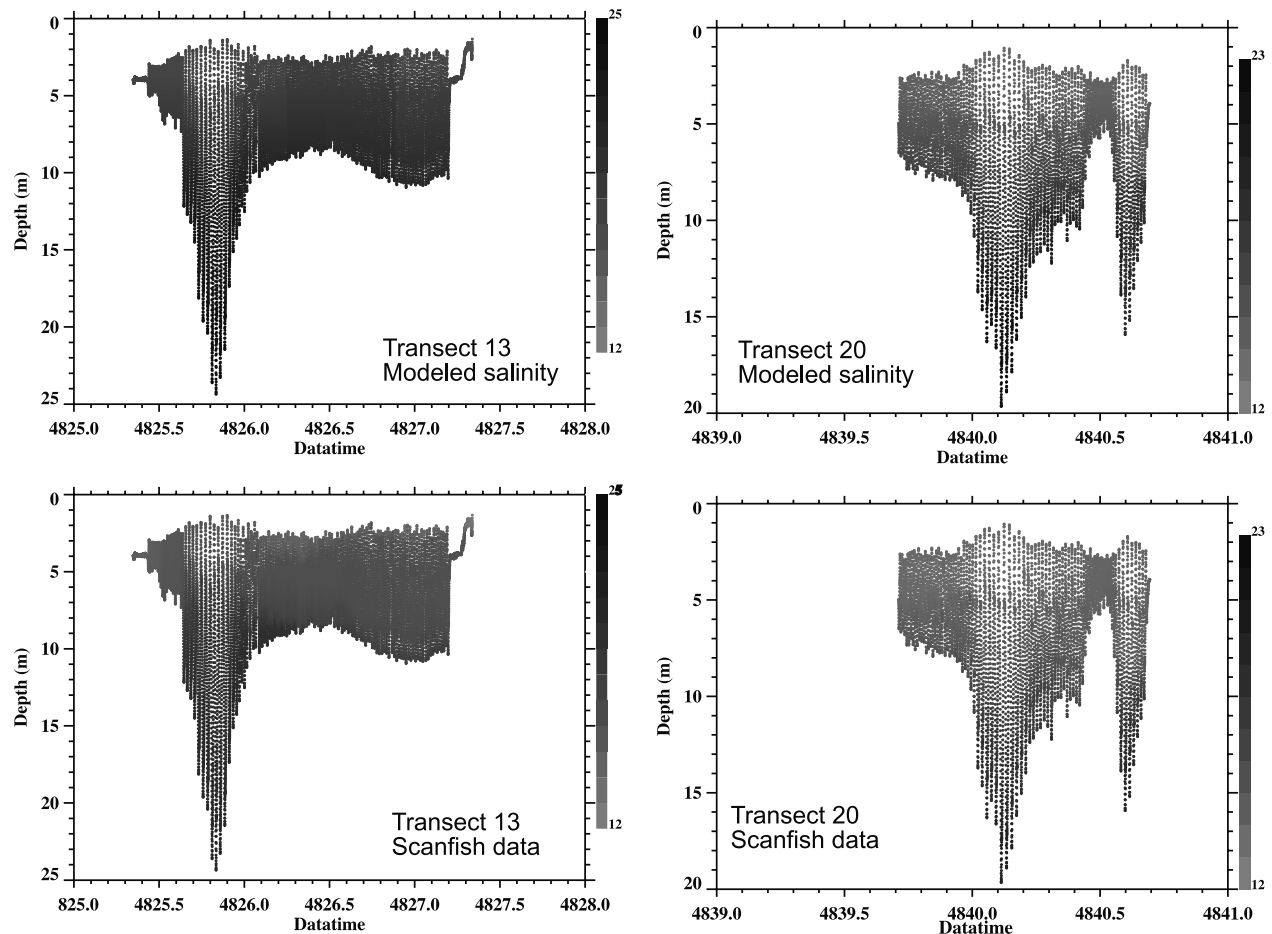

( a )

(b)

Figure 7. Vertical sections of salinity (psu) from the (top) model and (bottom) Scanfish measurements along (a) transect 13 and (b) transect 20 in July. Horizontal axes are time (in hours) in 1995. See color version of this figure at back of this issue.
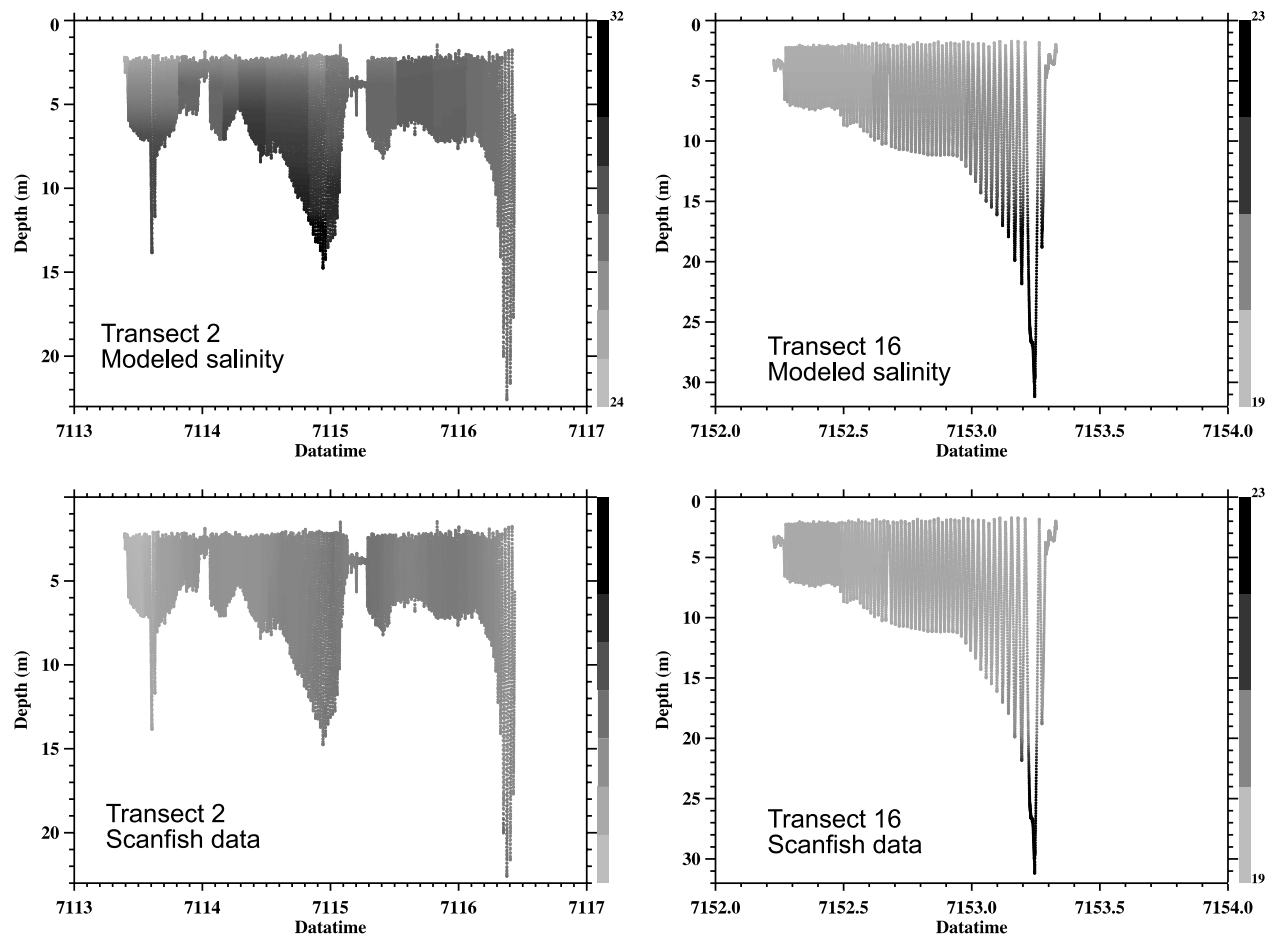

( a )

(b)

Figure 8. As in Figure 7 except along (a) transect 2 and (b) transect 16 in October. See color version of this figure at back of this issue. 


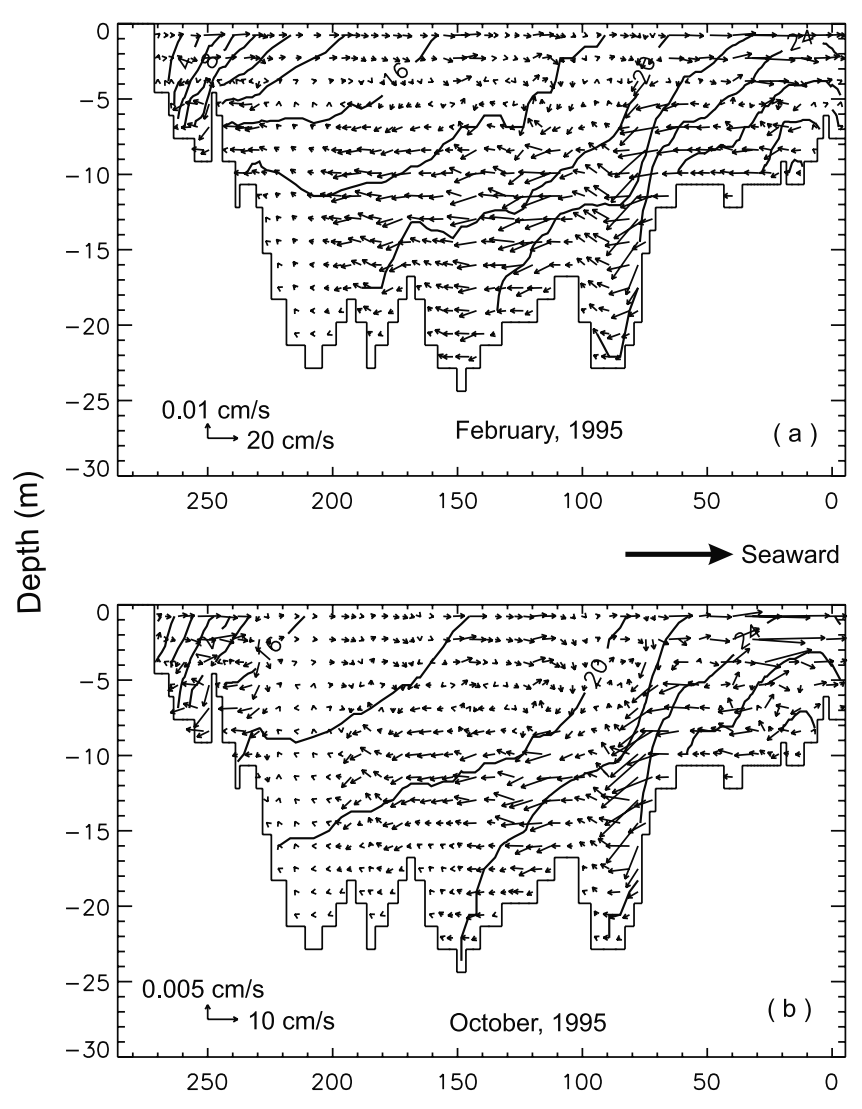

Distance from southern land boundary $(\mathrm{km})$

Figure 9. Longitudinal vertical sections of monthly averaged currents and salinity in (a) February and (b) October of 1995 before data are assimilated. The longitudinal section follows the center axis of deep channel southward to the mouth of Rappahannock River and thereafter extrapolates farther southward to the southern land boundary. Contour intervals for salinity are $2 \mathrm{psu}$.

grid point at $\left(x_{0}, y_{0}, z_{0}\right)$ may receive Scanfish data from distributed points $\left(x_{i}, y_{i}, z_{i}, t_{i}\right)$ in a four-dimensional neighborhood. The governing equation for salinity $S$ is

$$
\begin{aligned}
D S / D t= & {[\text { diffusion }]+K\left(S^{\text {obs }}-S\right) \max \left\{\operatorname { e x p } \left[-\left(x_{i}-x_{0}\right)^{2} / X^{2}\right.\right.} \\
& \left.\left.-\left(y_{i}-y_{0}\right)^{2} / Y^{2}-\left(z_{i}-z_{0}\right)^{2} / Z^{2}-\left(t_{i}-t_{0}\right)^{2} / T^{2}\right]\right\}
\end{aligned}
$$

where $D / D t$ is the substantial differential operator and [diffusion] accounts for turbulent mixing in three dimensions. In addition to advection and diffusion, the nudging term in (1) restores observed salinity at a fixed rate $K$. The Gaussian dependence in space ensures that the influence of a data point on a model grid point decays with distance away from the data point. The appropriate length scale of spatial decay is $X$ in the longitudinal direction, $Y$ in the lateral direction, and $Z$ in the vertical. A Gaussian time dependence ensures active data injection in a timescale $T$ before and after the data arrival. At any given time step of data insertion a model grid point must choose a point among distributed Scanfish data in a four-dimensional neighbor- hood to receive data. The winning data point at $\left(x_{i}, y_{i}, z_{i}, t_{i}\right)$ is the point making maximum contribution to a model grid point at $\left(x_{0}, y_{0}, z_{0}, t_{0}\right)$. In this light the observed salinity $\left(S^{\text {obs }}\right)$ in $(1)$ represents the salinity value of the winning data point.

[26] The assimilation procedure as outlined in the proceeding paragraph is computationally demanding. At any given time step of integration a winning data point must be chosen among millions for every grid point inside the model domain. The searching procedure is cumbersome and arises solely because the irregular distribution of Scanfish data is highly incompatible with modeled salinity fields. A few measures can be taken to speed up the search. For example, one can switch off the search routine if a model grid point is sufficiently away from Scanfish data in time or space. Further, the resolution of Scanfish data is unnecessarily high in terms of model needs. To enhance the efficiency of searching, the Scanfish data were subsampled at intervals of $5 \mathrm{~s}$ before they were used for data assimilation.

[27] For the assimilated results shown below the salinity restoration rate $K$ is chosen to be (15 hours $)^{-1}$. The value of $K$ needs to be large enough to make an impact while being small enough to avoid excitation of gravity waves. Haltiner and Williams [1980] suggested that the timescale for $K$ should be smaller than the dominant timescale contained in observations. In anticipation of a fast changing estuarine environment our timescale for $K$ is considerably shorter than typical values used in open ocean settings [Sarmiento and Bryan, 1982]. While the nudging improves the modeled salinity fields, it also triggers brief moments of readjustment in gravitational circulation. The readjustment may occur during and shortly after the data insertion period and brings unrealistic features into the model for a short period of time. In this light, $K$ is optimized to maximize the gain and minimize the loss caused by data injection. The choice of $e$-folding timescale, $T=6$ hours, is comparable to the timescale of semidiurnal tides. Nudging length scales $(X, Y$, and $Z)$ have also been optimized. For the solution shown below, longitudinal and lateral $(X$ and $Y)$ scales are set to 40 and $3 \mathrm{~km}$, respectively. Vertical scale $Z$ is considerably shorter; chosen to be $2 \mathrm{~m}$. Model sensitivity to $K, T, X, Y$, and $Z$ will be discussed later, after the discussion of main results.

\section{Gravitational Readjustment}

[28] The data assimilation may trigger renewed gravitational circulation because the density structure is significantly altered. Since each model or assimilation period varies in oceanographic setting and data availability, it is difficult to predict the timing and longitudinal extent of the readjustment. Nevertheless, the readjustment process documented below is likely to be encountered in a variety of models of long estuaries during periods of strong or moderate data injection. Prognostic models of long estuaries, if properly tuned to produce realistic features in the inner reaches, are likely to overestimate the salinity of bottom inflow especially near the estuary mouth. When data are inserted, the salinity is reduced in the mouth region and/or deeper reaches of the basin. The buoyant outflow may intrude farther seaward in response to the altered density structure. The strength of the renewed seaward 

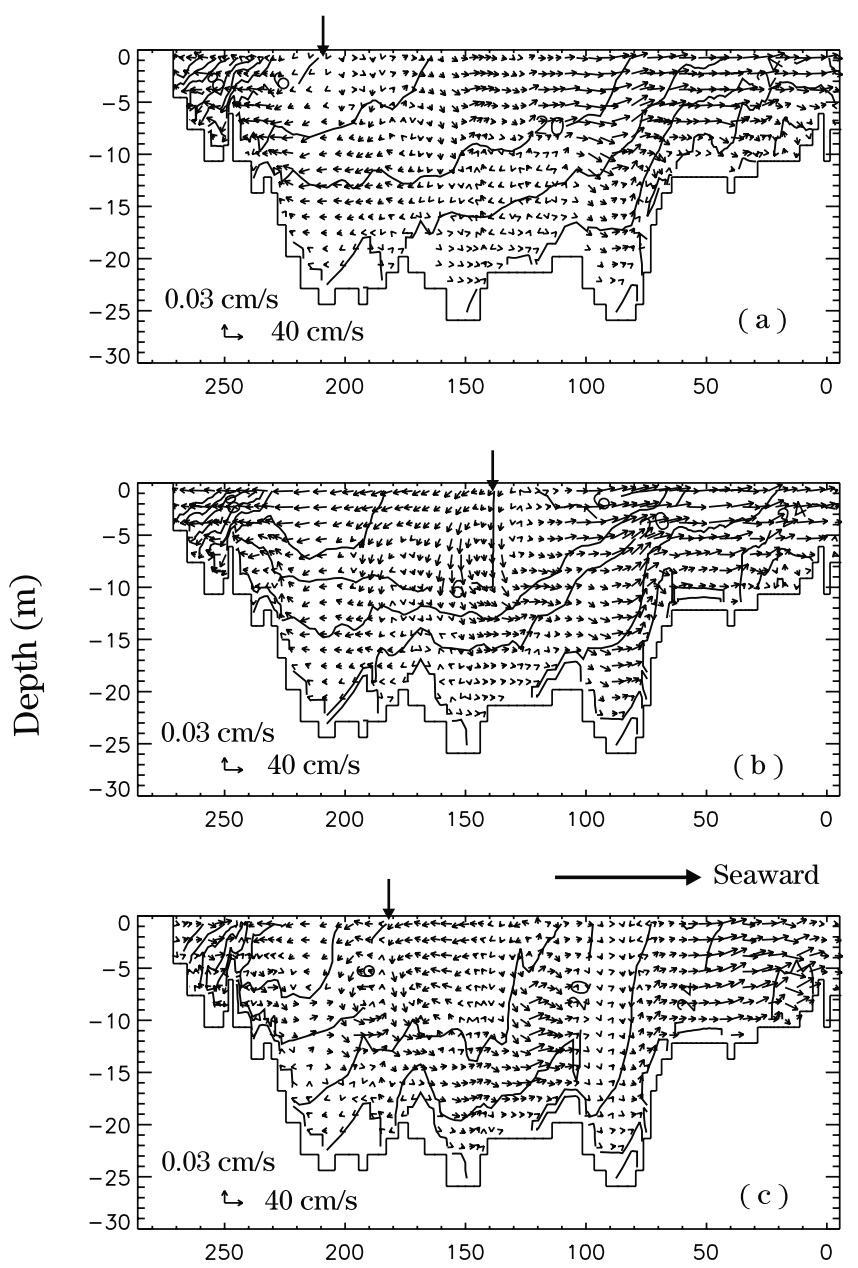

Distance from southern land boundary $(\mathrm{km})$

Figure 10. Longitudinal vertical sections of instantaneous currents and salinity (psu) at (a) 1130 LT on 23 October, (b) 1130 LT on 24 October, and (c) 2230 LT on 27 October 1995. Figures 10a, 10b, and 10c also correspond to the times right before the beginning of data assimilation, at 8 hours after the beginning of active data assimilation, and at 10 hours after the completion of data assimilation, respectively. Contour intervals for salinity are 2 psu.

expansion depends on the data injection speed. Further data injection in time will eliminate the undesirable transient and move the solution back to reality.

[29] In this model, high-resolution data were available only briefly in July and October. The data injection must be sufficiently strong to make a lasting impact. As a result of the strong nudging, the gravitational readjustment occurs preferably in the early stage of data assimilation in October, soon after the salinity data in lower reaches of the Bay are inserted. The readjustment will not occur if either July or October is excluded from data assimilation. The combination of the two assimilation periods is necessary to trigger it.

[30] Figure 10 shows flow and salinity fields on the longitudinal vertical section, as in Figure 9, before, during, and after the gravitational readjustment in October. These snapshots are instantaneous so that wind- and tide-induced currents are included. Locations of 16 psu isohalines are marked by arrows on top of each panel to highlight the gravitational readjustment. Shortly before data arrival (Figure 10a), brackish water is confined in upper reaches, and waters in lower reaches are quite saline. Figure 10b shows the same vertical section 24 hours later. The time corresponds to 8 hours after the beginning of active data assimilation or 2 hours after the Scanfish was deployed in October. Recall that active data assimilation begins in an $e$ folding timescale ( $T=6$ hours) before data arrival. At this time, data are inserted only in regions around and seaward of transect 5 in Figure 3. Nevertheless, the limited amount of data insertion is able to trigger a gravitational readjustment. As indicated by the 16 psu isohaline, the buoyant surface layer expands seaward by about $70 \mathrm{~km}$ in one spurt. Further, waters in lower reaches are freshened by about 2 psu or so. Thereafter continuous data insertion eliminates the artificial seaward expansion. Figure 10c shows the same section 10 hours after the October data assimilation ends. The snapshot is taken 84 hours after Figure 10b. The artificial seaward expansion of buoyant layer is eliminated, and the basin-wide salinity structure is moved closer to observations. Our analysis of root mean square errors in section 6 will confirm this point.

[31] It is worth pointing out that the salinity restoration rate $K$ is a crucial parameter controlling the strength and longitudinal extent of gravitational readjustment. With a larger $K$ the seaward expansion of the buoyant layer is greater, but subsequent data injection in middle and upper reaches of the bay also eliminates the readjustment at a faster rate. In the other extreme the readjustment process can be eliminated if $K$ becomes exceedingly small. Leaving $K$ aside, the longitudinal extent of data assimilation also influences the strength of gravitational readjustment. For example, one could limit the data insertion to upper and middle reaches of the bay only. The consequent gravitational readjustment would be weaker.

[32] It is conceptually useful to interpret the renewed gravitational circulation in terms of pressure changes. In the model-derived two-layered circulation the bottom inflow upwells and returns as a surface outflow. The gyre is maintained by proper pressure gradients. When data are assimilated in lower reaches of the bay, pressure is reduced near the mouth. The consequent increase in the seaward pressure gradient triggers the seaward expansion of the buoyant layer. If data are inserted only in middle and upper reaches, the effect is essentially to reduce salinity at depth. The consequent pressure deficit at depth enhances the bottom inflow of saline water from the mouth region. Thereafter the pressure field is temporarily reduced in lower reaches because of the sudden loss of salinity. This may also cause the layer of brackish water to expand seaward. Following this line of reasoning, the data insertion in lower bay has the immediate effect to encourage seaward expansion of the buoyant layer. The data injection in middle and upper reaches may also encourage the seaward expansion but only after the pressure field in the lower bay is reduced. Thus data assimilation in the lower bay has a more profound effect than insertions elsewhere insofar as the renewed gravitational readjustment is concerned. Our preliminary experiments by varying the region of assimilation lend support to the foregoing conclusion. 


\section{Model Improvement Through Data Assimilation}

[33] Despite the undesirable consequence of gravitational readjustment, the agreement between the model and the observations after data assimilation is generally improved. Salinity measurements at scattered stations in 1995 (Figure 3) provide an independent data set to evaluate the model performance. Discrepancies between the model and data are first evaluated in terms of root mean square (RMS) errors. Figure 11 illustrates the RMS error as a function of time in the upper, middle, and lower reaches of the bay. In Figure 11a each ensemble contains all data points collected north of the Choptank River in each month. The RMS error, ranging up to several psu, may have underrepresented the model's prognostic skill because salinity stations are fixed in space. A slight longitudinal shift of salinity patterns
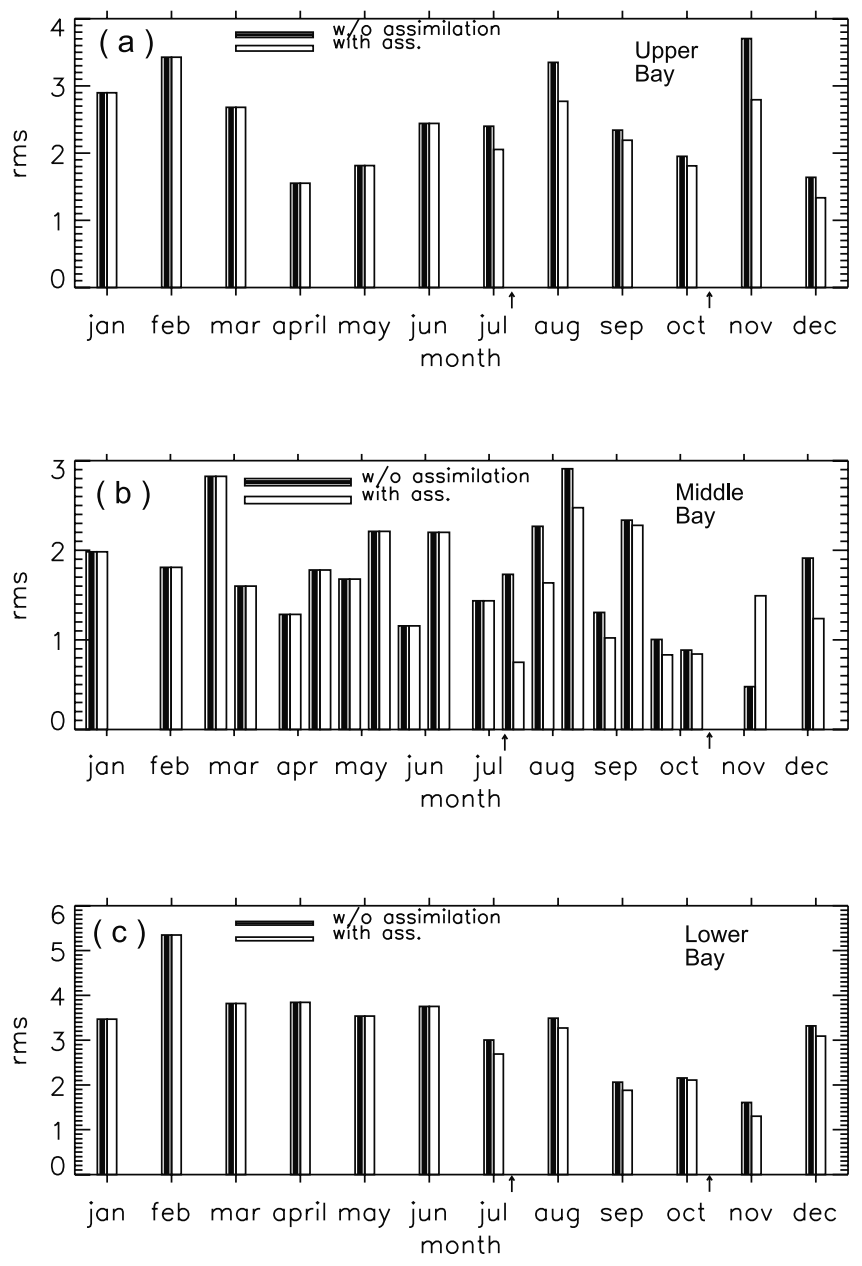

Figure 11. The RMS errors (in psu) between modeled and observed salinity values with and without data assimilation in the (a) upper, (b) middle, and (c) lower reaches of the Chesapeake Bay. With reference to Figure 3 the ensemble contains all data points collected in the upper reaches in Figure 11a, only data at station $\mathrm{CB} 4.3 \mathrm{C}$ in the middle reaches in Figure 11b, and all data in the lower reaches in Figure 11c. Temporally, data are grouped by the month except in Figure 11b. Arrows indicate the approximate time of data insertion.
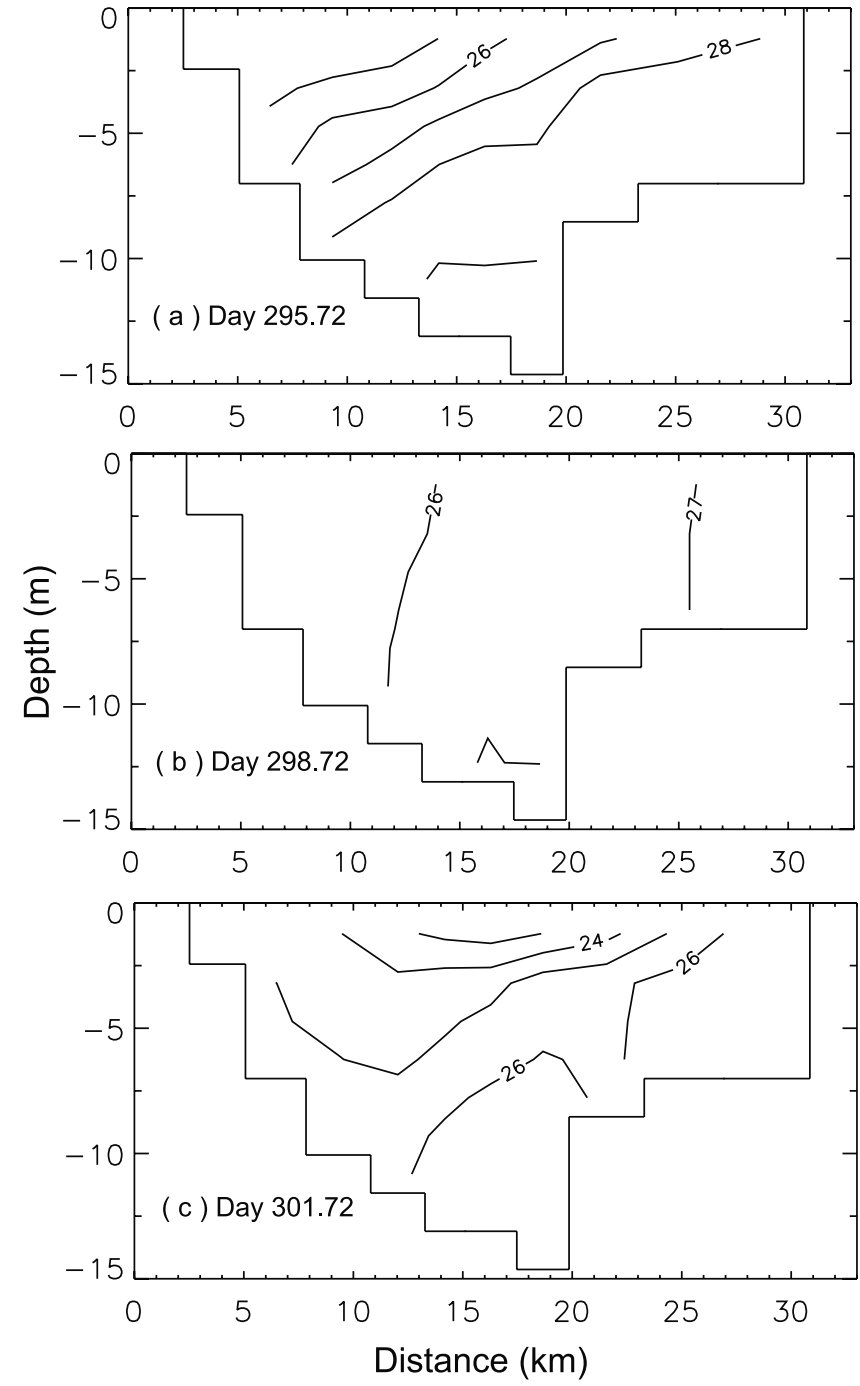

Figure 12. Zonal sections of model-derived salinity in October midway between Scanfish transects 3 and 4 in Figure 3: (a) shortly before data injection in the vicinity of this section (at day 295.72), (b) shortly after data injection at day 298.72 , and (c) day 301.72 . Fast changes of salinity at 3 day intervals indicate a quick loss of memory after data injection in the lower bay. The view is northward.

produced by the model may be seen as a large error at a fixed station. Leaving the magnitude of RMS errors aside, model improvements through data assimilation are apparent. Results from the pair of experiments, one with data assimilation and one without, contrast the difference brought about by data injections. The reduction in RMS errors is maximum in the month immediately following the July and October assimilation and decreases slowly thereafter.

[34] The model performance is similar at all salinity stations in the middle reaches of the bay; therefore only one station (CB4.3C) is chosen to illustrate the RMS error (Figure 11b). At this station, data are not grouped for each month, and each ensemble consists of only a vertical profile of salinity with $1 \sim 2 \mathrm{~m}$ resolution. The improvement brought about by data assimilation is generally more 

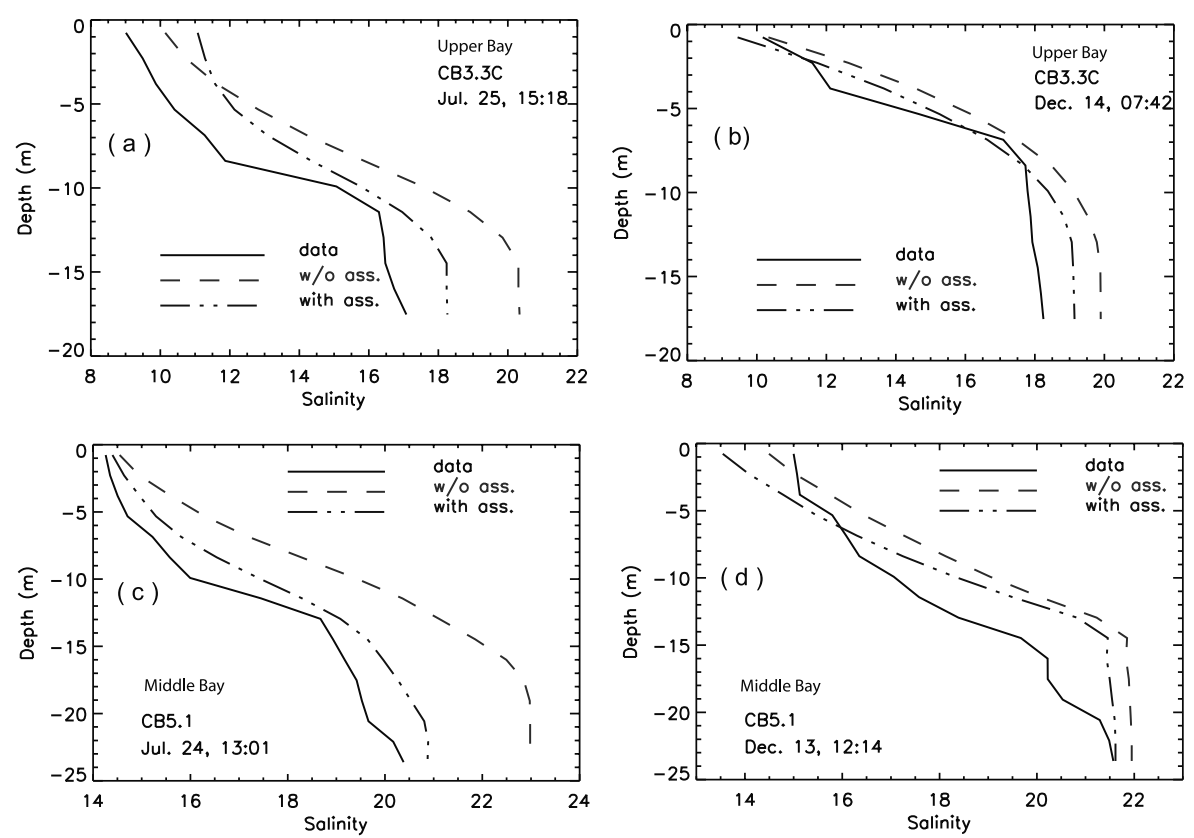

Figure 13. Comparisons among observed salinity profiles (solid), modeled salinity profiles without data assimilation (dashed), and modeled salinity profiles with data assimilation (dash-dotted) at selected stations: (a) and (b) station CB3.3C in the upper bay and (c) and (d) station CB5.1 in the middle bay. Times of comparison, as indicated in Figures 13a and 13c, are right after data assimilation in July and times in Figures $13 \mathrm{~b}$ and $13 \mathrm{~d}$ are about 1.5 months after active data insertions in October.

profound in the middle reaches than in the upper reaches, except during the brief period of gravitational readjustment. At the end of July the RMS error decreases twofold as a result of data insertions. The improvement diminishes slowly in time thereafter. After October data assimilation the RMS error actually increases over a brief period in November as a result of the gravitational readjustment. Thereafter the RMS error decreases again after the adjustment is over.

[35] Data insertions generally also enhance the model performance in the lower bay, but the improvement does not persist for a long time because the adjacent coastal sea is excluded from data assimilation. As in Figure 11a, each ensemble in Figure 11c contains all data points collected from stations south of Potomac River (Figure 3) in each month. The RMS errors decrease little after data injections.

[36] On a longer timescale, marginal improvements resulted in the lower bay despite massive injections of data with high spatial resolution. Shorter memories of flushing timescales in the lower bay are responsible for the deficiency. Figure 12 shows the model-produced variations of salinity structures in a zonal section midway between Scanfish transects 3 and 4, as indicated in Figure 3. Before the data arrival in October the salinity field (Figure 12a) shows considerable stratification. In reality, waters in the lower bay are typically less stratified in winter. Destratification occurs shortly after the data injection (Figure 12b), bringing the model closer to reality. Thereafter the stratification returns in time (Figure 12c). Apparently, the bottom inflow from the coastal ocean tends to reestablish the stratification. More illustrations of short flushing timescale in the lower bay will be given later in Figure 15.

[37] There are two ways to improve the model performance in the lower bay. One way is to inject continuously data with high temporal resolution in the lower bay. This measure, however, would defeat the purpose of the data assimilation scheme, which is meant to find ways to make lasting model improvements through occasional data injection. A more reasonable way would be to extend the assimilation areas to the adjacent coastal ocean. Without data assimilation the salinity of the coastal ocean is highly constrained by climatology; subsequent intrusion into the bay tends to offset the data injection effort especially in the lower bay. If high-resolution salinity data are available in the coastal ocean during the data assimilation period, assimilation of these data in the coastal ocean would sustain the effect of data assimilation in the lower bay for a longer period of time. This recommendation is not heeded herein for lack of qualified data off the bay mouth.

[38] In general, model improvements through the data assimilation are not depth sensitive. Figure 13 shows observed and modeled salinity profiles at selected stations. Figures $13 \mathrm{a}$ and $13 \mathrm{~b}$ are derived from station CB3.3C in the upper bay, while Figures $13 \mathrm{c}$ and $13 \mathrm{~d}$ are from station CB5.1 in the middle bay. Surface salinity data from these two stations have been used in the initial tuning of the model before data assimilation (Figure 5). Figure 13 indicates that the model improvements after July assimilation (Figures 13a and 13c) and October assimilation (Figures $13 \mathrm{~b}$ and $13 \mathrm{~d}$ ) do not favor a particular depth. With data assimilation the model-derived salinity profiles generally shift toward observed profiles at all depths with few exceptions.

[39] In the absence of concurrent flow measurements it is a bit uncertain whether the data assimilation actually improves the model-produced flow fields. However, the collective wisdom from previous modeling experiences 


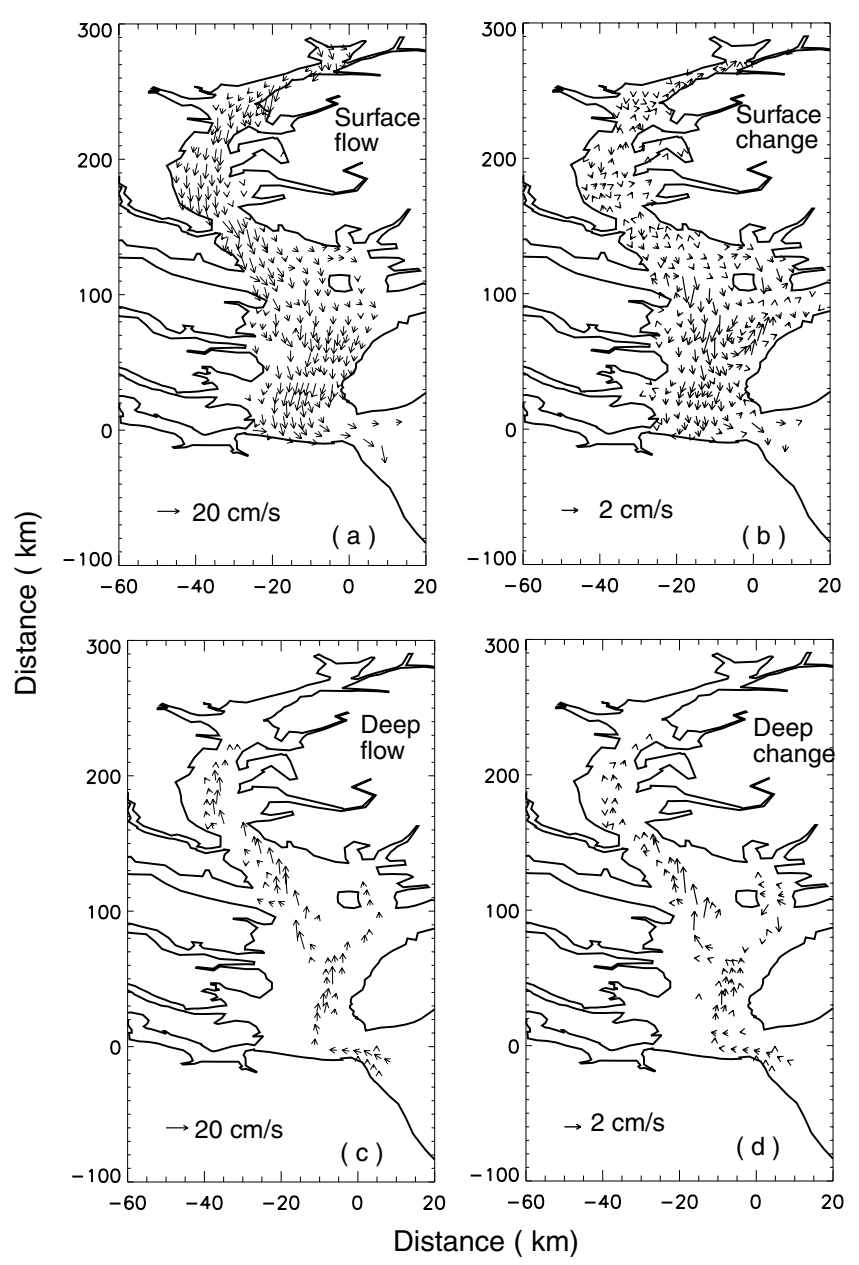

Figure 14. (a) and (c) Biweekly averaged flow fields without data assimilation and (b) and (d) corresponding changes caused by data assimilation. Time averaging is over the second and third weeks of November 1995. Figures 14a and $14 \mathrm{~b}$ are surface features, while Figures $14 \mathrm{c}$ and $14 \mathrm{~d}$ are taken at $10 \mathrm{~m}$ below mean water level. Zonal length scales and zonal velocities are stretched for clarity.

suggests that a more realistic density structure often supports a more realistic flow field. It is highly likely that the flow fields after the data assimilation are more realistic. Figure 14 illustrates the changes in the flow field induced by the data assimilation. Figures $14 \mathrm{a}$ and $14 \mathrm{c}$ are biweekly averaged flow fields at the surface (Figure 14a) and $10 \mathrm{~m}$ below mean water level (Figure 14c) without data insertions. The time average is over the middle 2 weeks in November (from day 310.5 to day 324.5). Since wind and tidal effects are filtered out through time averaging, the patterns are dominated by surface outflow and bottom inflow. Figures $14 \mathrm{~b}$ and $14 \mathrm{~d}$ show the corresponding difference caused by data assimilation. Leaving minor variations aside, it is clear that the data assimilation essentially enhances both the surface outflow and bottom inflow. The speed enhancement ranges up to about $4 \mathrm{~cm} \mathrm{~s}^{-1}$. Similar changes in the circulation pattern were also found in August and September (not shown here) after data assimilation in July. The result is not surprising in light of the fact that most ocean models tend to underestimate the strength of density- driven currents because of grid-scale mixing. Thus assimilation of hydrographic data appears to offer a remedy to offset numerical damping.

[40] Dynamically, the enhanced bottom inflow and surface outflow can be regarded as a renewed adjustment under gravity. To illustrate this, Figure 15 shows the time-averaged longitudinal section of density anomalies induced by data assimilation in October. The longitudinal section is the same as in Figures 9 and 10. Further, the time averaging is from day 295 to day 310.55 in Figure $15 \mathrm{a}$ and from day 310.55 to day 326.1 in Figure $15 \mathrm{~b}$. The averaging period in Figure 15a covers the time span of active data assimilation (roughly from day 296 to day 298). The density anomaly is obtained by subtracting model results without data assimilation from that with data assimilation. Since the time span extends to well after the period of active data assimilation, the density anomaly in Figure 15a does not correspond to a static change brought about solely by data assimilation. Dynamic adjustments also set in to change the density structure. Despite the complication, simple analyses below suggest that the density anomaly is becoming an integral part of the two-layered circulation.

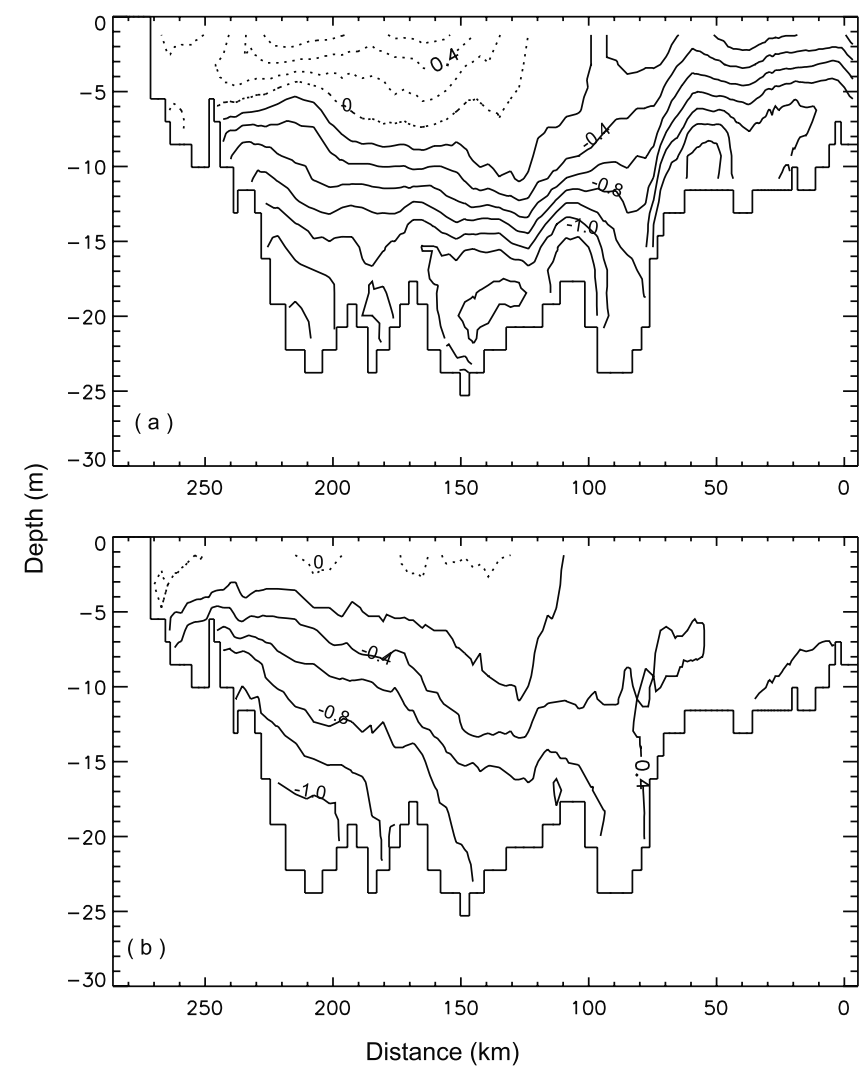

Figure 15. Biweekly averaged section of density $\left(\sigma_{t}\right)$ anomalies induced by the data assimilation in October along the main axis of the deep channel. Time averaging is (a) from day 295 to day 310.55 in panel and (b) from day 310.55 to day 326.1 . The longitudinal section is the same as in Figures 9 and 10. The density anomaly is obtained by subtracting the model result without data assimilation from that with data assimilation. Solid and dashed contours correspond to density deficit and density surplus, respectively. Contours intervals are $\Delta \sigma_{t}=0.2$. 
[41] The data assimilation essentially induces density deficits that intensify toward the bottom of the deep channel. Data injections also produce a patch of density surplus in upper depths, confined mostly in the upper and middle reaches of the bay. By comparison the bottomtrapped density deficit is the most dominant signal. Roughly speaking, the density deficit in Figure $15 \mathrm{a}$ is characterized by $\Delta \sigma_{t}=0.8$ over the bottom $10 \mathrm{~m}$ of the deep channel. The associated speed of internal gravity waves $\left(c_{0}\right)$ is about $28 \mathrm{~cm} \mathrm{~s}^{-1}$. The density deficit is mostly confined inside the estuary because the adjacent coastal ocean is excluded from data assimilation. In consequence, this density deficit would induce bottom inflow from the coastal ocean. Let $u_{0}$ be the characteristic inflow speed. In the absence of topography drag, mixing, and friction, inviscid theories such as Benja$\min [1968]$ would suggest an internal Froude number $\left(\mathrm{u}_{0} / \mathrm{c}_{0}\right)$ of order 1, and the two-layered circulation would be enhanced by $30 \mathrm{~cm} \mathrm{~s}^{-1}$ or so. The actual enhancement is only about $5 \mathrm{~cm} \mathrm{~s}^{-1}$ in Figure 14, suggesting a characteristic Froude number much below 1 in this partially mixed estuary.

[42] The low Froude number governs not only the perturbation field induced by data assimilation but also the mean circulation in the Chesapeake Bay. Relative to the seawater density near the bay mouth, the density deficit $(\Delta \sigma t)$ in the upper reaches of the bay is often in excess of 10 (see Goodrich et al. [1987] or Figure 9). The characteristic $c_{0}$ associated with this density deficit is about $100 \mathrm{~cm} \mathrm{~s}^{-1}$. Mean speeds of bottom inflow are generally below $20 \mathrm{~cm} \mathrm{~s}^{-1}$ (see Goodrich et al. [1987] or Figure 14). Thus the basin-scale mean circulation is also governed by a similarly low Froude number.

[43] Figure 15b provides an alternative to illustrate the faster loss of memory in the lower bay. Generally speaking, the density anomalies decrease slowly in time after the data injection. The enhancement of two-layered circulation by data injections also decreases in time accordingly. However, the density deficit diminishes much faster in the lower reaches of the bay, disappearing almost completely in Figure 15b. As commented on earlier, the fast disappearance arises because the adjacent coastal ocean is excluded from data assimilation.

\section{Discussion and Conclusions}

[44] Using a Chesapeake Bay model as a test case, assimilation of high-resolution Scanfish data proved to be a useful tool to enhance model performance if certain precautions are taken to minimize volatile transients induced by fast data injections. If nudging is strong, the consequent transient may manifest as renewed gravitational circulation. Subsequent data assimilation will eliminate the transient overshooting. Brief lapses of model accuracy may be inconvenient if one desires to obtain a continuous quality output. If this is the major concern, one can blend in the model result without data assimilation using a time-varying weighting function to eliminate the undesirable transient.

[45] Given a few narrow windows of high-resolution data in a year, the nudging must be strong enough to make a difference but also weak enough to minimize possible gravitational readjustment. The precaution is necessary because of the limited availability of high-resolution data.
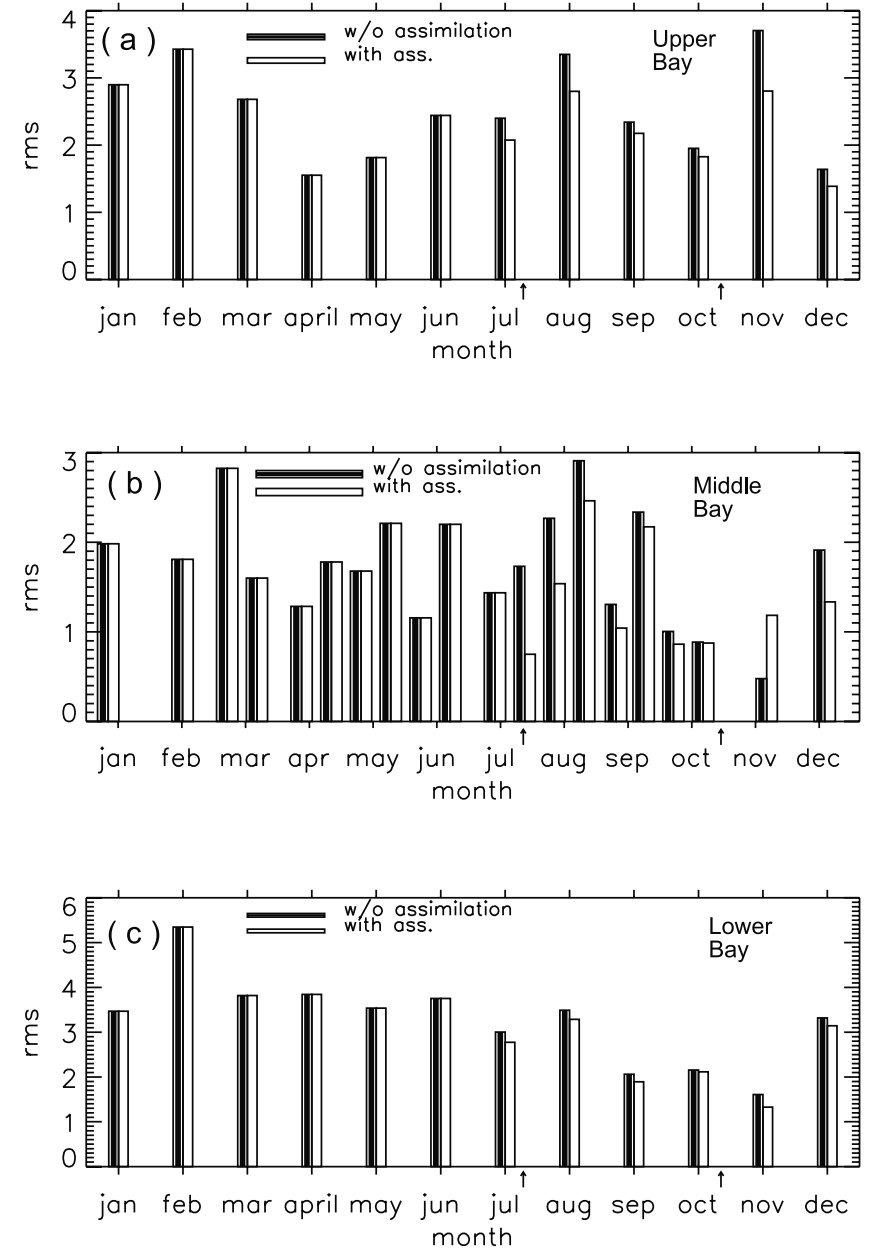

Figure A1. As in Figure 11 except $T$ is reduced threefold to 2 hours and $K$ is increased threefold to 5 hours $^{-1}$.

Ideally, the restoration rate of hydrographic data can be reduced to a bare minimum if the data string is more or less continuous in time. In this idealized setting, continuous nudging in time will minimize model discrepancies, and the nudging rate need not be large because the discrepancy is kept small at all times. It is highly likely that the undesirable overshooting can be eliminated in this limit. Leaving the idealized scenario aside, the choice of nudging rate $K$ must be optimized to maximize the gain and minimize the loss brought about by the data assimilation. When this is done, the gravitational circulation is normally enhanced after the data insertion, and the enhancement will last for months.

[46] In theory the amount of salinity anomaly received by the model from a single data point is linearly related to a four-dimensional volume ( $T, X, Y$, and $Z$ ) by the constant $K$. Since data continue to enter the model from different locations, the real relationship is quite complex. Nevertheless, $K$ and $T$ should be chosen to be inversely proportional to each other in order to maintain approximately the same intensity of nudging. Leaving $K$ and $T$ aside, the assimilation scheme still involves choices of proper length scales $(X, Y$, and $Z$ ) in the longitudinal, lateral, and vertical directions. The model is generally not sensitive to these choices as long as we maintain proper aspect ratios pertaining to the estuary 
basin. As a rule of thumb, the choice of $X$ must be commensurate with the tidal excursion length in the longitudinal direction. Once $X$ is fixed, $Y$ and $Z$ can be chosen proportionally to maintain the aspect ratios of the basin. After these choices are made, moderate variations in parameter space do not impact profoundly the model response.

[47] In the long run, repeated acquisitions of high-resolution hydrographic data would lead to climatological data sets for the basin. Climatological data are regularly distributed in time and space and therefore can be assimilated more efficiently into models. Additional gains from regularly spaced climatological data can also be anticipated in the future if we borrow similar experiences from the open ocean modeling community. Through assimilation of regularly spaced climatological data we may be able to adjust other variables such as sea level, vorticity, and currents or to infer boundary currents in a dynamically consistent manner to maximize the gain. Similar methodology has been advanced considerably in the open ocean setting; see, for example, Ezer and Mellor [1994], Forbes and Brown [1996], and Wu et al. [1999] for several interesting applications. Our experiment with manually adjusting open boundary conditions using data assimilation improved the model considerably. At the present time it is not clear what dynamic constraints should be enforced when nudging several variables simultaneously in a tidally dominated estuarine environment. While the methodology still awaits future development, the simple assimilation scheme presented herein draws attention to this issue and makes a modest start.

\section{Appendix A: A Shorter Assimilation Timescale}

[48] One reviewer suggested that a shorter $e$-folding timescale ( $T=1 \sim 2$ hours) should be used for data assimilation in estuaries. Obviously, the choice of $T$ should be constrained by the dominant tidal period (12.42 hours). Our numerical results indicate that this is a loose constraint. As long as $T$ is not completely decoupled from the tidal period, the assimilation scheme achieves similar results if the restoration rate $K$ and $T$ are inversely proportional to each other.

[49] Taking the reviewer's comment as an example, we can reduce $T$ threefold (from 6 to 2 hours) and increase $K$ threefold (from 15 to 5 hours $^{-1}$ ) to achieve similar effects. Figure A1 illustrates resulting RMS errors as functions of time in the upper, middle, and lower reaches of the bay. Figure A1 is produced following the same recipe as that of Figure 11; a comparison between Figures A1 and 11 highlights the insensitivity of the assimilation scheme to the $e$-folding assimilation timescale. In the upper bay the new $e$-folding timescale leads to similar reduction in RMS errors. In the middle reaches, improvements after data assimilation and discrepancies induced by the brief gravitational readjustment after October are comparable to that in Figure 11. Improvements in the lower bay are as marginal as before. Since the difference between Figures 11 and A1 is small, other details will not be presented.

[50] Acknowledgments. Cathy Lascara and Russ Burgett of Old Dominion University kindly helped us with the IDL code for retrieving and visualizing the Scanfish data. Authors J. X. and R. R. H. were supported by NASA grant NAG5-6286 and National Science Foundation grant
OCE96-28888. Author S. Y. C. was supported by the National Science Foundation under grant DEB-94-12113. This is UMCES contribution 3503.

\section{References}

Anthes, D. L. T., Data assimilation and initialization of hurricane-predicting models, J. Atmos. Sci., 31, 702-719, 1974.

Benjamin, T. B., Gravity currents and related phenomena, J. Fluid Mech., 31, 209-248, 1968.

Blumberg, A. F., and G. L. Mellor, A description of a three-dimensional coastal ocean circulation model, in Three-Dimensional Coastal Ocean Models, Estuarine Sci., vol. 4, edited by N. S. Heaps, pp. 1-16, AGU, Washington, D. C., 1987.

Bogden, P. S., and J. O'Donnell, Generalized inverse with shipboard current measurements: Tides and nontidal flows in Long Island Sound, $J$. Mar. Res., 56, 995-1027, 1998.

Bogden, P. S., P. Malanotte-Rizzoli, and R. Signell, Open-ocean boundary conditions from interior data: Local and remote forcing of Massachusetts Bay, J. Geophys. Res., 101, 6487-6500, 1996.

Edinger, J. E., D. K. Brady, and J. C. Geyer, Heat exchange and transport in the environment, Rep. 14, Electric Power Res. Inst., Palo Alto, Calif., 1974.

Ezer, T., and G. K. Mellor, Continuous assimilation of Geosat altimeter data into a three-dimensional primitive equation Gulf Stream model, J. Phys. Oceanogr., 24, 832-847, 1994.

Forbes, C., and O. Brown, Assimilation of sea surface height data into an isopycnic ocean model, J. Phys. Oceanogr., 26, 1189-1213, 1996.

Goodrich, D. M., W. C. Boicourt, P. Hamilton, and D. W. Pritchard, Windinduced destratificaiton in Chesapeake Bay, J. Phys. Oceanogr., 17, 2232-2240, 1987.

Haltiner, G. J., and R. T. Williams, Numerical Prediction and Dynamic Meteorology, 477 pp., John Wiley, New York, 1980.

Hood, R. R., H. V. Wang, J. E. Purcell, E. D. Houde, and L. W. Harding Jr., Modeling particles and pelagic organisms in Chesapeake Bay: Convergent features control plankton distributions, J. Geophys. Res., 104, $1223-1243,1999$.

Ippen, A. T., Tidal dynamics in Estuaries, part I, Estuaries of rectangular section, in Estuary and Coastline Hydrodynamics, edited by A. T. Ippen, 744 pp., McGraw-Hill, New York, 1966.

Johnson, B. H., K. W. Kim, R. H. Heath, H. L. Butler, and B. B. Hsieh, Development and verification of a three-dimensional numerical hydrodynamic, salinity, and temperature model of the Chesapeake Bay, Tech. Rep. HL-91-7, U.S. Army Eng. Waterw. Exp. Stn., Vicksburg, Miss., 1991.

Kundu, P. K., A numerical investigation of mixed layer dynamics, J. Phys. Oceanogr., 10, 220-236, 1980.

Launder, B. E., and D. B. Spalding, The numerical calculation of turbulence flows, Comp. Methods Appl. Mech. Eng., 3, 269-289, 1974.

Levitus, S., Climatological atlas of the world ocean, NOAA Prof. Pap.13, 173 pp., U.S. Govt. Print. Off., Washington, D. C., 1982.

Sarmiento, J. L., and K. Bryan, An ocean transport model for the North Atlantic, J. Geophys. Res., 87, 394-408, 1982.

Sheng, Y. P., A three-dimensional mathematical model of coastal, estuarine and lake currents using a boundary fitted grid, Rep. 585, ARAR Group, Titan Syst., Princeton, N. J., 1986.

Spitz, Y. H., and J. M. Klinck, Estimate of bottom and surface stress during a spring-neap tide cycle by dynamical assimilation of tide gauge observations in the Chesapeake Bay, J. Geophys. Res., 103, 12,761-12,782, 1998.

Wang, D.-P., Subtidal sea level variations in the Chesapeake Bay and relation to atmospheric forcing, J. Phys. Oceanogr., 9, 413-421, 1979a.

Wang, D.-P., Wind-driven circulation in the Chesapeake Bay, winter 1975, J. Phys. Oceanogr., 9, 564-572, 1979 b.

Wang, H. V., and R. S. Chapman, Application of vertical turbulence closure schemes in the Chesapeake Bay circulation model-A comparative study, Estuarine and Coastal Modeling, edited by M. L. Spaulding and R. T. Cheng, pp. 283-297, Am. Soc. of Civ. Eng., Reston, Va., 1995.

Wu, C. R., P. T. Shaw, and S. Y. Chao, Assimilating altimetric data into a South China Sea model, J. Geophys. Res., 104, 29,987-30,005, 1999.

W. C. Boicourt, S.-Y. Chao, R. R. Hood, and J. Xu, University of Maryland Center for Environmental Science, Cambridge, MD 21613, USA. (boicourt@hpl.umces.edu; chao@hpl.umces.edu; raleigh@hpl.umces.edu; jiangtao@hpl.umces.edu)

H. V. Wang, Department of Physical Sciences, Virginia Institute of Marine Science, Greate Road, Route 1208, Gloucester Point, VA 23062, USA. (wang@vims.edu) 

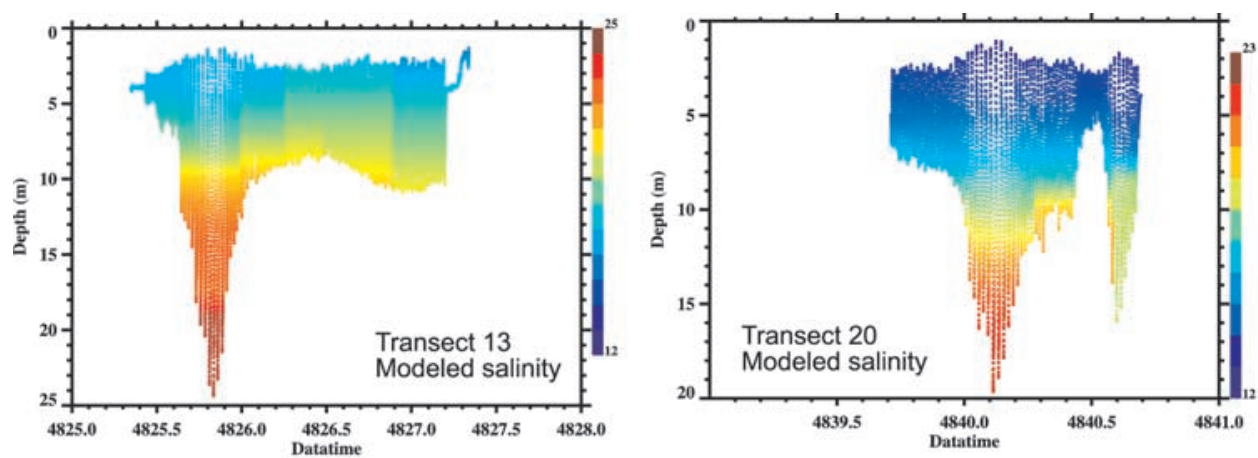

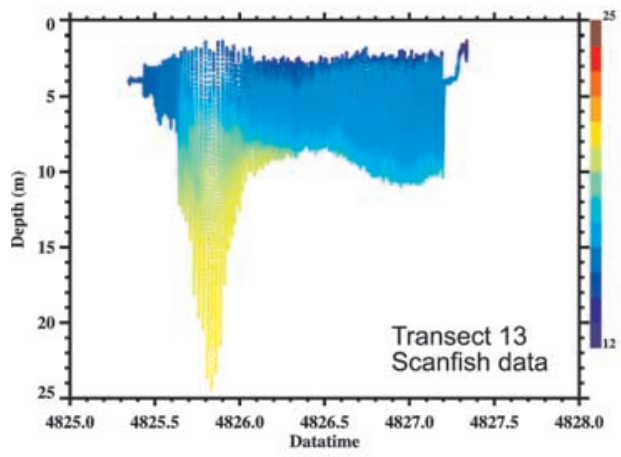

(a)

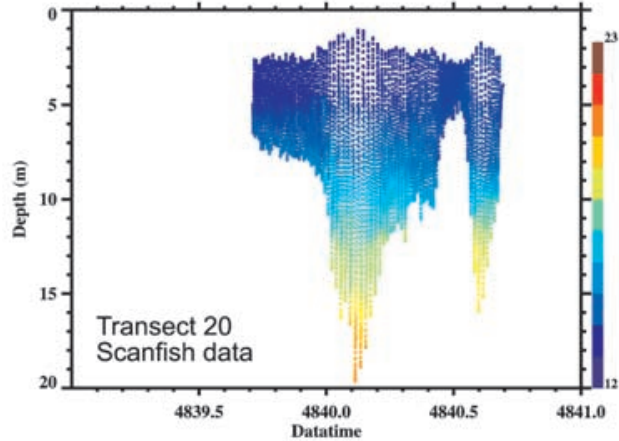

(b)

Figure 7. Vertical sections of salinity (psu) from the (top) model and (bottom) Scanfish measurements along (a) transect 13 and (b) transect 20 in July. Horizontal axes are time (in hours) in 1995.
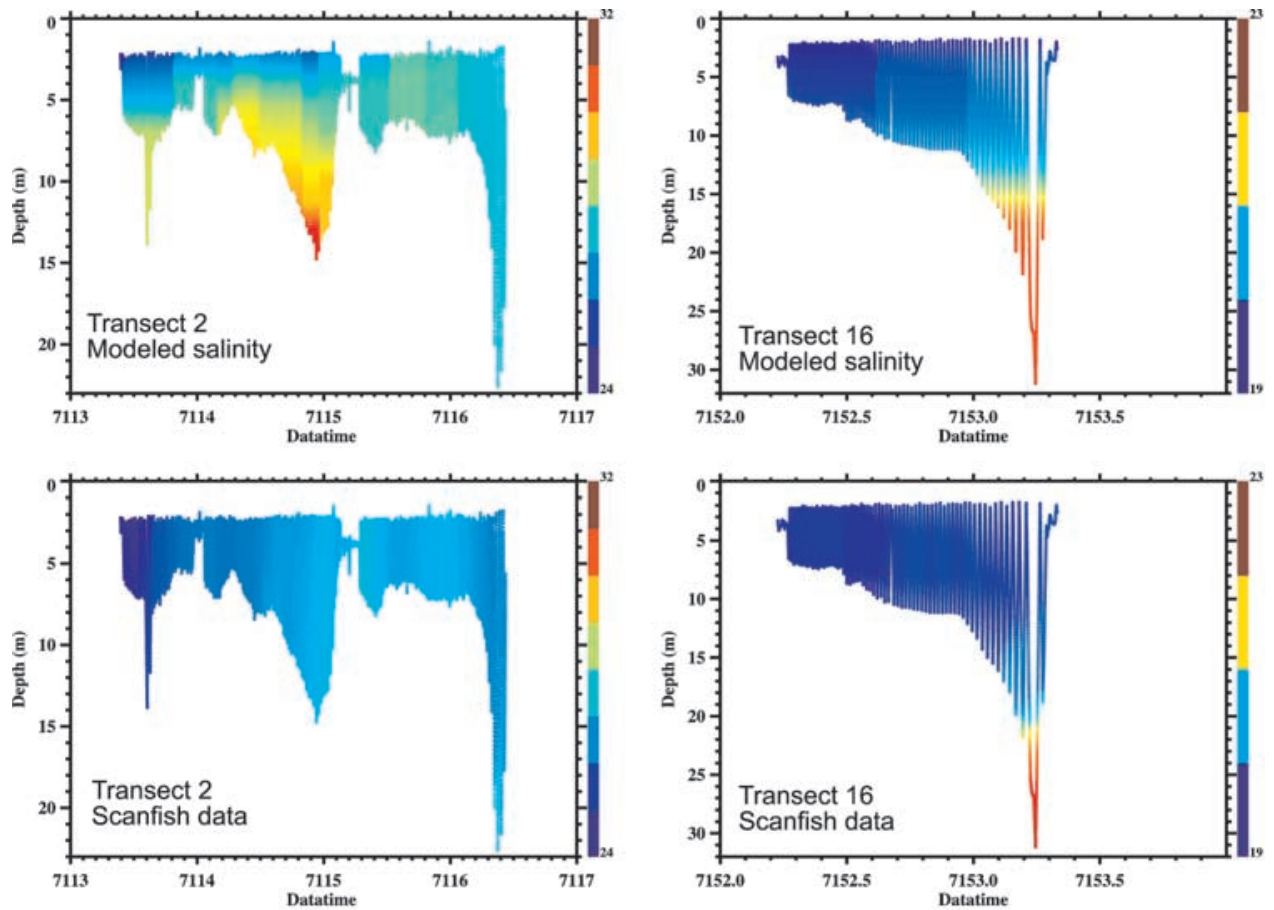

(a)

(b)

Figure 8. As in Figure 7 except along (a) transect 2 and (b) transect 16 in October. 